OPEN ACCESS

Edited by:

Ignacio Moreno De Alborán Spanish National Research Council, Spain

Reviewed by: Valeria Poli, University of Turin, Italy Javier Leon,

Univesity of Cantabria, Spain

*Correspondence: Alessio Zippo zippo@ingm.org

Specialty section:

This article was submitted to Molecular and Cellular Oncology, a section of the journal Frontiers in Cell and Developmental

Biology

Received: 12 October 2016

Accepted: 20 January 2017

Published: 03 February 2017

Citation:

Fagnocchi L and Zippo A (2017) Multiple Roles of MYC in Integrating Regulatory Networks of Pluripotent Stem Cells. Front. Cell Dev. Biol. 5:7. doi: 10.3389/fcell.2017.00007

\section{Multiple Roles of MYC in Integrating Regulatory Networks of Pluripotent Stem Cells}

\author{
Luca Fagnocchi ${ }^{1,2}$ and Alessio Zippo ${ }^{1,2 *}$ \\ ${ }^{1}$ Department of Epigenetics, Fondazione Istituto Nazionale di Genetica Molecolare "Romeo ed Enrica Invernizzi" (INGM), \\ Milan, Italy, ${ }^{2}$ Division of Pathology, Fondazione IRCCS Ca' Granda, Ospedale Maggiore Policlinico, Milan, Italy
}

Pluripotent stem cells (PSCs) are defined by their self-renewal potential, which permits their unlimited propagation, and their pluripotency, being able to generate cell of the three embryonic lineages. These properties render PSCs a valuable tool for both basic and medical research. To induce and stabilize the pluripotent state, complex circuitries involving signaling pathways, transcription regulators and epigenetic mechanisms converge on a core transcriptional regulatory network of PSCs, thus determining their cell identity. Among the transcription factors, MYC represents a central hub, which modulates and integrates multiple mechanisms involved both in the maintenance of pluripotency and in cell reprogramming. Indeed, it instructs the PSC-specific cell cycle, metabolism and epigenetic landscape, contributes to limit exit from pluripotency and modulates signaling cascades affecting the PSC identity. Moreover, MYC extends its regulation on pluripotency by controlling PSC-specific non-coding RNAs. In this report, we review the MYC-controlled networks, which support the pluripotent state and discuss how their perturbation could affect cell identity. We further discuss recent finding demonstrating a central role of MYC in triggering epigenetic memory in PSCs, which depends on the establishment of a WNT-centered self-reinforcing circuit. Finally, we comment on the therapeutic implications of the role of MYC in affecting PSCs. Indeed, PSCs are used for both disease and cancer modeling and to derive cells for regenerative medicine. For these reasons, unraveling the MYC-mediated mechanism in those cells is fundamental to exploit their full potential and to identify therapeutic targets.

Keywords: MYC, pluripotent stem cells, transcription regulatory networks, epigenetics, signaling pathways, epigenetic memory, cancer

\section{PLURIPOTENT STEM CELLS IDENTITY}

Pluripotent stem cells (PSCs) possess two defining properties: they are able to indefinitely selfrenew, thus maintaining their cell identity after cell division, and they are pluripotent, having the potential to differentiate toward all cell lineages of the organism. Those properties have made PSCs an attractive tool in many research areas such as developmental studies (Keller, 2005; Niwa, 2010), regenerative medicine (Cohen and Melton, 2011; Wu and Hochedlinger, 2011; Cherry and Daley, 2012), drugs discovery (Grskovic et al., 2011; Avior et al., 2016), disease and cancer modeling (Zhu et al., 2011; Bellin et al., 2012; Robinton and Daley, 2012; Kim and Zaret, 2015; Laplane et al., 2015; Zeltner and Studer, 2015; Avior et al., 2016). 
In vivo, PSCs are a transient cell population emerging approximately at embryonic day 3.5 (E3.5) in mouse embryos, and are confined to the inner cell mass (ICM) of the blastocyst, which will further differentiate giving rise to all embryonic tissues (Cockburn and Rossant, 2010). Despite this transient existence during embryogenesis, many different PSCs have been derived and indefinitely maintained in vitro, including embryonic stem cells (ESCs) derived from the ICM (Evans and Kaufman, 1981; Martin, 1981; Thomson et al., 1998), post-implantation epiblastderived stem cells (EpiSCs) (Brons et al., 2007; Tesar et al., 2007), and induced PSCs (iPSCs), obtained through the reprogramming of somatic cells (Takahashi and Yamanaka, 2006; Takahashi et al., 2007).

The in vitro derivation and maintenance of all those PSCs is strictly dependent on provided extrinsic signals, as PSCs continuously balance their self-renewal and differentiation potential in response to environmental cues, which are integrated with the epigenetic machinery and the transcriptional regulatory network (TRN), governing cell identity (Chen et al., 2008; Ying et al., 2008; Ng and Surani, 2011; Clevers et al., 2014; Fagnocchi et al., 2016b). Thus, to identify the molecular mechanisms which are responsible for pluripotency is fundamental to fully exploit the potential of PSCs. Our major understanding of the TRN governing pluripotency comes from studies on mouse ESCs (mESCs), which lead to the identification of the core transcription factors (TFs) required for their cell identity: Oct4 (also known as Pou5f1), Sox2 and Nanog (collectively known as OSN). Oct4 and Nanog were identified as core TFs of pluripotency due to their specific expression during early development and in ESCs, and were demonstrated to affect both the establishment and the maintenance of a stable pluripotent state both in vivo and in vitro (Nichols et al., 1998; Avilion et al., 2003; Chambers et al., 2003; Mitsui et al., 2003; Loh et al., 2006). Even if ESCs can be propagated in absence of Nanog and it is expressed at low levels in mouse EpiSCs, it is required for the formation of the ICM in vivo and widely

Abbreviations: 2i, two inhibitor; $\alpha$-KG, $\alpha$-ketoglutarate; bHLH-LZ, basic helix-loop-helix leucine-zipper; BMP4, bone morphogenetic protein 4; CDKs, cyclin-dependent kinases; CHIR, CHIR99021; CoA, acetyl-coenzyme A; dKO, MYC/MYCN double knock-out; DNMTs, DNA methyltransferases; DUSP2/7/9, dual specific phosphatases 2/7/9; EpiSCs, epiblast-derived stem cells; ESCC, ESCspecific cell-cycle regulating miRNAs; ESCs, embryonic stem cells; ETC, electron transport chain; FAD, flavin adenine dinucleotide; FGF2, basic fibroblast growth factor; H3K27me3, histone 3 lysine 27 tri-methylation; H3K4me1/2/3, histone 3 lysine 4 mono-/di-/tri-methylation; H3K9ac, histone 3 lysine 9 acetylation; H3K9me1/2/3, histone 3 lysine 9 mono-/di-/tri-methylation; HDACs, histone deacetylases; HDMs, histone demethylases; hESCs, human ESCs; ICM, inner cell mass; iPSCs, induced pluripotent stem cells; JAK-STAT3, Janus kinasesignal transducer and acti-vator of transcription 3; lncRNAs, long non-coding RNAs; MBI-IV, MYC boxes I-IV; mESCs, mouse ESCs; miRNAs, micro RNAs; MYC-ER, MYC ${ }^{\mathrm{T} 58 \mathrm{~A}}$-estrogen receptor; NAD, adenine dinucleotide nicotinamide; ncRNAs, non-coding RNAs; NLS, nuclear localization sequence; OHT, 4hydroxytamoxifen; OSK, OCT4/SOX2/KLF4; OSKM, OCT4/SOX2/KLF4/MYC; OSN, OCT4/SOX2/NANOG; Oxphos, oxidative phosphorylation; PcG, polycomb group proteins; PD03, PD0325901; PRC1, polycomb repressive complex 1; PRC2, polycomb repressive complex 2; PRMT7, protein arginine methyltransferase 7; PSCs, pluripotent stem cells; RB, retinoblastoma tumor suppressor; SAM, Sadenosylmethionine; TAD, transactivation domain; TFs, transcription factors; TGF $\beta$, transforming growth factor- $\beta$; TRN, transcriptional regulatory network; TSA, trichostatin A; VPA, valproic acid. co-localize with Oct4 and Sox2 in ESCs (Chambers et al., 2007; Marson et al., 2008; Silva et al., 2009). Oct4 functions as a heterodimer with Sox2 and they act sinergically, activating distal regulatory elements which control multiple pluripotency factors (Avilion et al., 2003; Masui et al., 2007). Importantly, mapped OSN targets show extensive overlap between mESCs and human ESCs (hESCs), pointing toward the existence of a conserved core TRN (Boyer et al., 2005; Loh et al., 2006). The OSN core positively regulates their own promoters, generating an interconnected auto-regulatory loop and exerts its role by concomitantly sustaining pluripotency and self-renewal factors, while restricting differentiation by repressing lineage-specificing TFs. When OSN are expressed at optimal levels, ESCs are stably maintained, while their perturbation leads to exit pluripotency and cell differentiation (Chambers et al., 2007; Toyooka et al., 2008; Karwacki-Neisius et al., 2013). Of note, an extended TRN have been elucidated in mESCs, comprising multiple TFs and downstream effectors of signaling pathways, which influence the ability of OSN to sustain PSCs identity (e.g.,: Klf4, Klf2, Dax1, Nac1, Zfp281, Essrb, Sall4, Tbx3, Prdm14, Stat3, Smad1, and Tcf3) (Niwa et al., 1998; Chen et al., 2008; Cole et al., 2008; Kim et al., 2008; Ng and Surani, 2011; Fagnocchi et al., 2016b).

Among the TFs which have been shown to play a crucial role for PSCs identity, MYC family members MYC and MYCN modulate both the establishment and the maintenance of PSCs (Chappell and Dalton, 2013). Indeed, co-deletion of both $m y c$ and mycn disrupts the maintenance of ESCs and iPSCs, while favoring their differentiation (Cartwright et al., 2005; Smith et al., 2010; Varlakhanova et al., 2010; Fagnocchi et al., 2016a). In addition MYC is essential to efficiently generate fully reprogrammed mouse and human iPSC, by enhancing OSN activity in the early steps of reprogramming (Takahashi and Yamanaka, 2006; Takahashi et al., 2007; Soufi et al., 2012). In this review, we will provide a brief overview on MYC transcription factors and then focus on the multiple mechanisms through which they can favor the pluripotent state, by integrating their transcriptional regulation activity with signaling pathways and epigenetic players. Finally, we will discuss the potential therapeutic implications of the described MYCdependent regulatory networks.

\section{MYC TRANSCRIPTION FACTORS}

MYC (also called c-MYC) was first identified more than 30 years ago as a cellular homolog of the $v$-myc oncogene of the avian myelocytomatosis retrovirus (Hayward et al., 1981; Vennstrom et al., 1982). It belongs to a basic helix-loophelix leucine-zipper (bHLH-LZ) family of TFs comprising also MYCN and MYCL, which are evolutionarily conserved and share significant protein sequence similarities. MYC proteins comprise an N-terminal transactivation domain (TAD), several conserved motifs named MYC boxes (MBI, II, III, and IV), which have been described to be important for MYC multiple activities, a nuclear localization sequence (NLS) and a C-terminal region with the bHLH and the LZ domains, fundamental in mediating DNA binding and also protein-protein interactions. (Cole and 
Cowling, 2008). Generally MYC requires to heterodimerize with the bHLH-LZ protein MAX in order to bind the canonical E-box elements (CACGTG) or other non-canonical variants (CANNTG) (Blackwell et al., 1990, 1993; Blackwood and Eisenman, 1991; Solomon et al., 1993; Lin et al., 2012). MYC binding sites frequently correlate with active promoters, which are enriched for DNase I hypersensitive sites, active chromatin marks and CpG islands (Fernandez et al., 2003; Guccione et al., 2006; Zeller et al., 2006; Kim et al., 2008). This chromatin patter is well in line with the finding that MYC cannot act as a pioneer TF but rather requires an open chromatin context to access DNA, as found in iPSC (Soufi et al., 2012). More recently, ChIP-seq data demonstrated that MYC also localizes at distal regulatory elements, in a cell type and concentration-dependent manner, binding enhancer regions when highly expressed (Lin et al., 2012; Nie et al., 2012; Sabo et al., 2014; Walz et al., 2014).

At the functional level, MYC is a relatively weak transcriptional modulator, leading to small changes of its target genes. It exerts its functions by interplaying with a large set of other TFs, co-activators or by recruiting chromatin modifiers ( $\mathrm{Tu}$ et al., 2015). MYC binding has been predominantly associated with activation of its target genes, accomplished through the recruitment of chromatin modifying factors (such as histone acetyltransferases) or by directly interacting with transcriptional co-activators (such as Mediator and P-TEFb complex), finally leading to release of stalled RNA polymerase II complex and to transcriptional elongation (Cole and Nikiforov, 2006; Zippo et al., 2007, 2009). Nonetheless, different mechanisms through which MYC mediates transcriptional repression have also been described, among which the best documented is the interaction with the transcription factor MIZ-1 (Seoane et al., 2001; Staller et al., 2001; Herkert and Eilers, 2010; Walz et al., 2014). Recently, the selective activity of MYC to transcriptionally modulate its targets has been challenged by the finding that it can eventually invade all active elements in the genome, mediating or potentiating their transcription, thus acting as a general "amplifier" (Lin et al., 2012; Nie et al., 2012). However, this phenomenon strictly depends on both the cell type and the level of expression of MYC, it does not account for genes that are repressed by MYC and it has been proposed as a secondary effect of MYC-mediated modulation of specific targets (Kress et al., 2015). In spite of the large amount of both RNA and chromatin profiling available, a unified model explaining the mechanism of MYC in modulating transcription is, indeed, still not available.

Under physiological conditions, MYC proteins have wellestablished pivotal roles in influencing basic cellular processes such as cell-cycle progression, cell proliferation and growth, cell size, energy metabolism, DNA replication, RNA production, differentiation and apoptosis (Eilers and Eisenman, 2008; Van Riggelen et al., 2010; Dang, 2013). For this reason, during adult tissues homeostasis, MYC expression is finely regulated by transcriptional, post-transcriptional and posttranslational regulatory mechanisms (Levens, 2010; Farrell and Sears, 2014) and typically maintained at low levels or restricted to regenerating and proliferating cells (such as in epidermis and gut). On the other hand, being such a critic hub for cell regulatory networks, its over-expression is a hallmark associated to up to the
70\% of all human cancers (Dang, 2012; Ciriello et al., 2013; Gabay et al., 2014). Both MYC and MYCN have a well-documented transforming capacity of cells in vitro, while MYCL is deficient in oncogenic potential (Land et al., 1983; Barrett et al., 1992). During tumorigenesis, over-expression of MYC is achieved either directly through gene amplification or translocation, or indirectly through mis-regulation of the many signaling pathways which are themselves targets of oncogenic mutations and regulate its expression under physiological conditions (e.g., Ras, Wnt, and Notch) (Dang, 2012). In addition to drive cancer initiation, MYC is also responsible for its maintenance: in several MYCdriven mouse tumor models, blocking MYC activity elicits tumor regression by promoting growth arrest and apoptosis and inducing cell differentiation, such as in sarcoma and hepatocellular cancer (Felsher and Bishop, 1999; Jain et al., 2002; Pelengaris et al., 2002; Shachaf et al., 2004). Finally, MYC seems also to play a crucial role in tumors driven by other oncogenes (e.g., RAS and SV40 T antigen), as targeting endogenous MYC leads to their regression (Soucek et al., 2008; Sodir et al., 2011). Altogether these evidences underline the potential of targeting MYC and its modulated targets for cancer therapy.

\section{ROLE OF MYC IN THE MAINTENANCE OF PSCS}

MYC-mediated maintenance of PSCs relies on its central role in cellular complex regulatory networks, integrating environmental signaling pathways with transcriptional and epigenetic modulations (Figure 1). In the following sections we will discuss in details the various mechanisms through which MYC sustains PSC identity.

\section{MYC TFs in Early Embryonic Development}

The first evidence supporting the implication of MYC TFs in sustaining pluripotency is represented by their role during embryonic development. At the pre- and early post-implantation embryonic stages, MYC and MYCN share the same expression profiles and are functionally redundant, as MYCN can substitute MYC throughout development, leading to viable and fertile adult mice (Zimmerman et al., 1986; Malynn et al., 2000). As a consequence, single knock-out mutations on either myc or mycn do not cause developmental defects before gastrulation. In addition, pluripotent and self-renewing ESCs can be derived from ICM lacking either $m y c$ or mycn. At mid-gestation stage, instead, their expression starts to diversify, leading to abnormalities: $m y c$ null embryos arrest at E10.5, showing growth, cardiac, neural, hematopoietic and vascular defects, and delay or failure in turning of the embryo (Davis et al., 1993; Trumpp et al., 2001; Baudino et al., 2002; Dubois et al., 2008); mycn knock-out embryos die between E10.5 and E12.5, exhibiting aberrations in limb bud, visceral organs (lung, stomach, liver, and heart) and the central/peripheral nervous systems (Charron et al., 1992; Stanton et al., 1992; Sawai et al., 1993). On the contrary, MYCL is totally dispensable during the whole embryogenesis and $\mathrm{mycl}^{-/-}$mice, expressing MYC or MYCN, are viable without abnormalities (Hatton et al., 1996). 


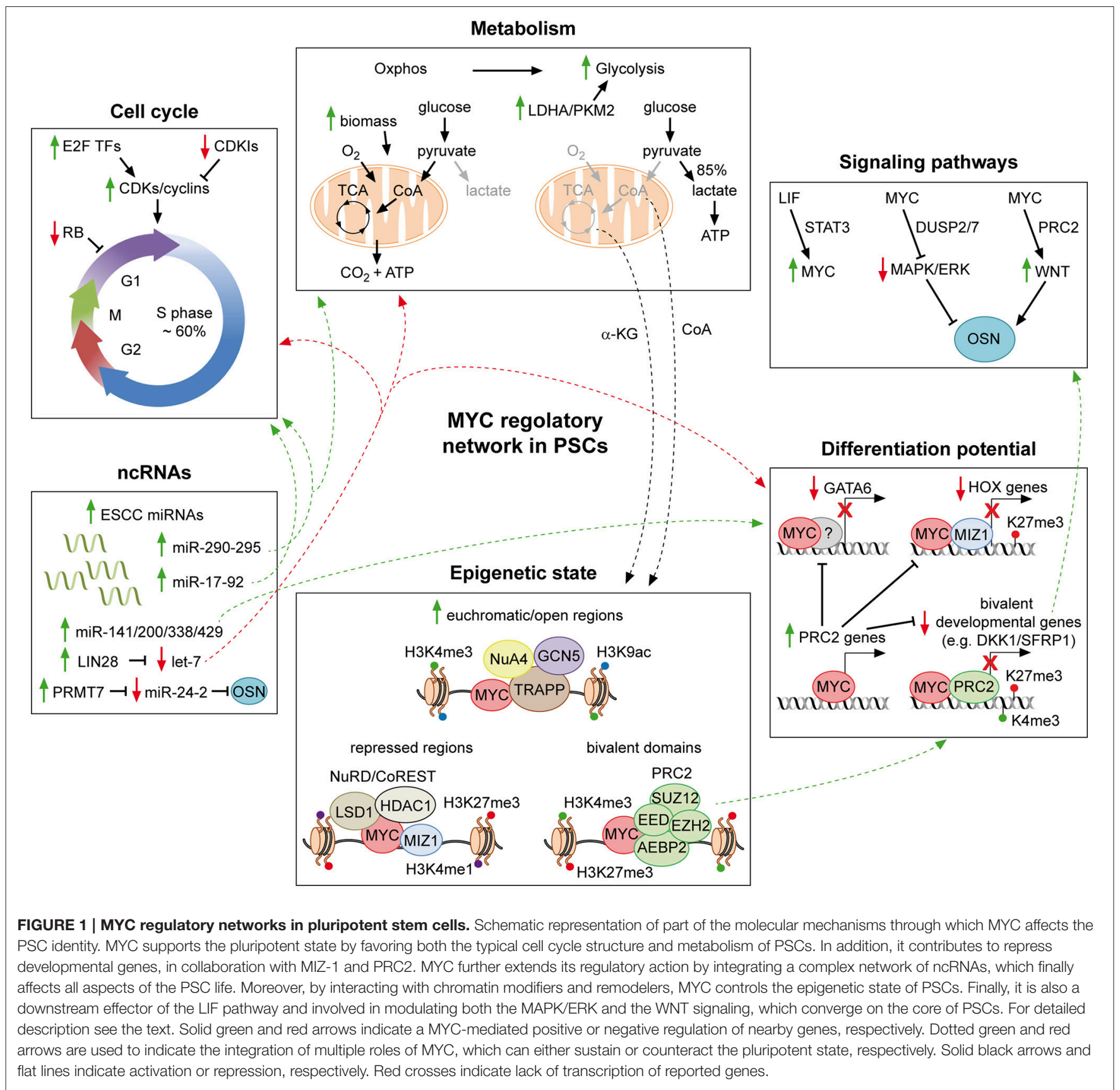

In spite of the absence of defects related to myc or mycn single null mutants, two key works demonstrated that the expression of at least one of the two genes is mandatory during murine early embryonic development (Smith et al., 2010; Varlakhanova et al., 2010). Concomitant disruption of $m y c$ and mycn triggers spontaneous differentiation of ESCs and iPSCs toward primitive endoderm and mesoderm, and embryos injected with ESCs lacking both MYC TFs predominantly failed to generate chimeras or survived only during the early development until mid-gestation, with severe defects. Importantly, re-expression of either myc or mycn was sufficient to restore PSCs identity, while MYCL failed to complement the double knockout defects. Likewise, single loss of either myc or mycn is inconsequential in hematopoietic stem cells, but their concurrent deletion is lethal (Laurenti et al., 2008). These evidences support the idea that MYC and MYCN are redundant but essential to determine the PSCs identity during pre-implantation stages of embryogenesis, when the ESCs of the ICM are established, whereas MYCL, although expressed in multiple organs during embryo development, is dispensable. 


\section{The MYC Module and the Regulatory Networks of PSCs}

In the last decade, the circuitry regulating PSC identity has been deeply investigated by means of next generation sequencing, in order to identify the genomic localization of functionally relevant TFs and the transcriptional outcome of their binding (Boyer et al., 2005; Loh et al., 2006; Chen et al., 2008; Cole et al., 2008; Kim et al., 2008, 2010). These analyses were mainly performed in murine ESCs and led to the possibility to simplify their complex regulatory networks by breaking them up into distinct units, also called "modules" (Kim et al., 2010). Three units were defined in mESCs, according to the co-binding of selected factors: The core, the polycomb and the MYC modules. As stated above, the TFs belonging to the core module comprises not only the proto-typical OSN, but also other TFs and terminal components of signaling pathways ( $\mathrm{Ng}$ and Surani, 2011; Fagnocchi et al., 2016b). The concomitant binding of multiple core TFs on both promoters and enhancers leads to the transcriptional activation of hundreds of target genes, whose expression is required for ESCs maintenance but then get turned off upon cell lineage commitment (Chen et al., 2008; Kim et al., 2008). On the contrary, the polycomb module comprises targets of the polycomb repressive complex 1 (PRC1) and PRC2, which include differentiation- and development-related genes (Bernstein et al., 2006; Boyer et al., 2006; Lee et al., 2006). Importantly, there is almost no overlap between the core and the polycomb modules, as they are involved in different functions.

The MYC module was first defined in ESCs as the common targets of MYC, MYCN, and other factors (such as MAX, DMAP1, ZFX, E2F1, E2F4, TRIM28, and CNOT) and comprised over 500 genes, which were not shared with neither the core nor the polycomb modules (Chen et al., 2008; Hu et al., 2009; Kim et al., 2010). Subsequent analysis on multiple genome wide binding studies showed that MYC binds as much as 8000 targets in ESCs, which are, indeed, clearly distinct from those regulated by either core TFs or PRC1/2 (Smith et al., 2011). This suggests that the global function of MYC in supporting PSCs identity is not solely relying on its direct binding and modulation of well-established pluripotency or lineage specification genes, but rather on its central role as integrator of multiple gene networks, which finally converge onto and influence the core module. In fact, this "enlarged MYC module" comprises genes related to functions distinctly important for the maintenance of self-renewal and pluripotency, such as cell-cycle progression, cell growth and metabolic regulation (Kim et al., 2010; Smith et al., 2011). Importantly, functionally relevant exceptions to this general activity of MYC have been described: for example MYC binds and regulates the genes coding for both SOX2 and the endoderm master regulator GATA6, thus directly affecting the core TRN and lineage differentiation, respectively (Lin et al., 2009b; Smith et al., 2010). Furthermore, MYC affects pluripotency by transcriptionally regulating different clusters of micro RNAs (miRNAs) and inhibits cell differentiation by directly and indirectly modulating developmental related genes and PRC1/2 components (Lin et al., 2009b; Smith and Dalton, 2010; Neri et al., 2012; Fagnocchi et al., 2016a). Finally, the role of MYC as a central integrator of multiple circuits in PSCs is underlined by its connection with epigenetic players and signaling pathway components, both influencing the pluripotent core module (Chen et al., 2008; Smith and Dalton, 2010; Chappell and Dalton, 2013; Fagnocchi et al., 2016a). Interestingly, the MYC module was also found to be highly expressed in cancer cells and to be predictive of cancer outcomes (Kim et al., 2010), emphasizing the potential therapeutic implications of unraveling the MYC-mediated regulatory circuitry in PSCs.

\section{MYC and Cell Cycle Control}

PSCs posses peculiar cell cycle duration time and structure, which differ to the ones of committed somatic cells (Figure 1, upper left panel). During embryogenesis, PSCs of the pre- and early post-implantation stages divide at unusually rapid rates (with an estimated generation time as brief as $4.4 \mathrm{~h}$ ), to support the expansion in cell number of the developing embryo. Those rapid cell cycles comprise truncated G1/G2 gap phases and 50-60\% of their time consists in DNA replication ( $\mathrm{S}$ phase), which is alternated with rounds of chromosome segregation ( $M$ phase). On the contrary, after the first cell fate commitment during gastrulation, cell cycle is restructured and dilated to $16 \mathrm{~h}$ or more. At this time of development, most cells spend the majority of their time in extended G1/G2 phases (Snow, 1977; Mac Auley et al., 1993; Power and Tam, 1993; Stead et al., 2002; Faast et al., 2004). Importantly, the peculiar cell cycle pattern occurring within the ICM is recapitulated by in vitro cultured PSCs and is conserved among different species. (Stead et al., 2002; White et al., 2005; Fluckiger et al., 2006; Tesar et al., 2007).

The molecular mechanisms underpinning these unusual cell cycles have been investigated in mESCs. These studies showed that cyclin-dependent kinases (CDKs) are constitutively active and expressed to significantly elevated levels in mESCs with respect to committed cells, where their expression become cell cycle regulated and oscillates in a strictly periodic manner (Stead et al., 2002; Faast et al., 2004). As a consequence, the retinoblastoma tumor suppressor (RB) is constantly inactiveted due to its CDKs-mediated hyper-phosphorylation, thereby the major G1 checkpoint (the R-point) is lost and cell division is mitogen-independent (Savatier et al., 1994). In addition, CDK inhibitory molecules (CDKIs) are also not expressed in mESCs, supporting constitutive activity of CDK and rapid cell divisions (Faast et al., 2004; White et al., 2005). Despite sharing a similar cell cycle pattern with mESCs, hESCs possess slower timing of division and display cycle-dependent expression of CDKs and regulation of $\mathrm{RB}$, and increased level of CDKIs, similarly to differentiated somatic cells. Thus, alternative molecular regulation of cell cycle must exist in hESCs, which have been shown to require the activity of CDK1/2 (Neganova et al., 2009, 2011, 2014).

The central role of MYC in affecting the timing and pattern of cell cycle in PSCs is underlined during early embryogenesis. Upon the first commitment of PSCs, MYC levels collapse and cell cycle structure acquires the typical somatic cell characteristics. Accordingly, genome wide binding analysis demonstrates that 
cell cycle regulators, such as cyclins, $\mathrm{CDKs}$ and $\mathrm{E} 2 \mathrm{~F}$ TFs are widely enriched among MYC targets in PSCs (Kidder et al., 2008; Kim et al., 2008; Smith et al., 2011; Nie et al., 2012; Bretones et al., 2015). Indeed, elevated MYC activity accelerates the progression toward G1 and increases the cell division rate and cell proliferation. On the contrary, concomitant $m y c$ and mycn null ESC mutants possess shortened $\mathrm{S}$ and lengthened G1 phases (Smith et al., 2010). Mechanistically, MYC can either directly activate transcription of several cyclins and CDKs (such as cyclin A, B1, D1/2, and E2, and CDK1, 4, 6, and 7 in PSCs) or indirectly modulate their protein stability by regulating $\mathrm{CDK}$ activating kinases $(\mathrm{CAK})$ and $\mathrm{CDC} 25$ family phosphatases (Smith and Dalton, 2010; Bretones et al., 2015). In addition, MYC suppresses CDKIs, such as p21 ${ }^{\mathrm{Cip} 1}$, p2 $7^{\mathrm{Kip} 1}$ and INK4 family members, by either antagonizing MIZ-1, recruiting chromatin modifiers or transcriptionally modulating other regulators (Brenner et al., 2005; Bretones et al., 2015). Moreover, both MYC and MYCN have been demonstrated to physically interact with $\mathrm{RB}$ and favor the loss of the R-point cell cycle arrest (Rustgi et al., 1991; Goodrich and Lee, 1992). Finally, MYC extends its control on cell cycle regulators by modulating the expression of miRNAs clusters, as discussed below in details. This role of MYC in sustaining PSCs specific cell cycle structure is relevant to facilitate their proliferation and maintain their long term identity. Indeed, cells preferentially initiate differentiation from G1 phase, suggesting that short G1 would limit the differentiation potential of PSCs, by impeding the complex chromatin remodeling required to exit pluripotency (Filipczyk et al., 2007; Singh and Dalton, 2009; Sela et al., 2012; Pauklin and Vallier, 2013; Dalton, 2015). Importantly, PSC cell cycle peculiar traits are reminiscent of tumor cells, in which cell cycle is deregulated independently from extrinsic mitogenes.

\section{MYC and Metabolic Regulation}

As it happens for cell cycle, the metabolism of PSCs also differs considerably from that of committed cells, due to different availability of oxygen and substrates which those cells experience. Somatic cells normally generate energy through carbon sources oxidation and production of reducing agents which triggers the electron transport chain (ETC) and leads to oxidative phosphorylation (Oxphos) (Figure 1, upper central panel). On the contrary, PSCs possess less mitochondrial content than differentiated counterparts and shift their metabolism to aerobic glycolysis, reminding the Warburg effect typical of highly proliferating tumor cells (Warburg, 1956; Van Blerkom, 2009; Moussaieff et al., 2015a). Despite the fact that PSCs mainly rely on glycolysis to produce energy (Zhang et al., 2012), different state of pluripotency are characterized by the use of different metabolic pathways. PSCs from the ICM at preimplantation stage produce energy by using mainly Oxphos rather than glycolysis, and are recapitulated in vitro by mESCs. On the contrary, immediately after implantation, the embryo is inefficiently vascularized and oxygen availability is limited, therefore energy production relies mainly on glycolysis, similarly to the metabolic state of murine EpiSCs and hESCs (Leese, 2012; Ryall et al., 2015). Finally, recently derived naïve hESCs, resembling human ICM cells, exhibit an even higher glycolytic flux accompanied by Oxphos (Carbognin et al., 2016; Gu et al., 2016). The reason why different PSCs utilize diverse metabolic pathways is still debated. Importantly, recent findings point toward the idea that cellular metabolism is not only a mere consequence of the cellular environment but rather is an active mechanism affecting PSCs identity in multiple ways. In addition to generating energy, metabolism supports PSCs identity by providing both the molecular intermediates required to sustain rapid cellular divisions and growth (Vander Heiden et al., 2009; Lunt and Vander Heiden, 2011) and metabolites influencing their epigenome (Shyh-Chang et al., 2013; Shiraki et al., 2014; Carey et al., 2015; Moussaieff et al., 2015a,b).

In this sense, the well-documented role of MYC in modulating metabolic related enzymes, energy production and biomass accumulation assume particular relevance for its ability to support PSCs identity. MYC regulates the glucose metabolism, by stimulating virtually all genes involved in both glycolysis and glutaminolysis, it favors the synthesis of nucleotides, proteins and lipids, thus supporting cell growth and proliferation and, finally, it is involved in mitochondrial and ribosomal biogenesis (Dang, 2013; Stine et al., 2015). Recent evidences underline the importance of MYC in regulating the glycolitic metabolism of both mouse and human ESCs (Cao et al., 2015; Gu et al., 2016). Cao et al. (2015) demonstrated that, when MBD2-mediated repression of MYC is alleviated by the miR-290 cluster of miRNAs, it directly binds to the promoter of two key relevant glycolytic enzymes, namely PKM2 and LDHA, activating their expression and enhancing the glycolytic metabolic switch of mESCs. Accordingly $m y c^{-/-}$mESCs show diminished glycolityc signature. The same molecular mechanism seems to be conserved in humans and favors the reprogramming of human fibroblasts. $\mathrm{Gu}$ et al. (2016), instead, showed that an increased glycolytic flux, functionally relevant to support the PSC state, occurs during the transition from naïve to primed hESCs and this correlates with augmented MYC transcriptional activity and elevated levels of nuclear MYCN. In particular, MYC-driven glycolysis depends on MCT1, a monocarboxylates membrane transporter. In accordance with this, chemical inhibition of either MYCN or MCT1 results in decreased proliferation of naïve hESCs. Furthermore, in addition to directly modulating the metabolism, MYC is also hard-wired into miRNAs networks affecting metabolic pathways, as discussed below. Finally, several recent works demonstrate how metabolic intermediates, such as $\alpha$-ketoglutarate $(\alpha-K G)$, S-adenosylmethionine (SAM), acetyl-coenzyme A (CoA), nicotinamide adenine dinucleotide (NAD), and flavin adenine dinucleotide (FAD) influence histone acetylation and DNA/histone methylation in PSCs, thus regulating their maintenance or differentiation (ShyhChang et al., 2013; Shiraki et al., 2014; Carey et al., 2015; Ryall et al., 2015; Moussaieff et al., 2015a,b). MYCmediated modulation of processes such as glycolysis and glutaminolysis, which alters the availability of $\alpha-\mathrm{KG}$ and CoA, suggests that it may also affect the epigenome of PSCs as a consequence, even though this hypothesis has to be formally proven yet. 


\section{MYC Regulation of the Differentiation Potential of PSCs}

PSCs identity depends on the continuous balance between their self-renewal and differentiation potentials. While the core TFs reinforce the expression of pluripotency genes, they also contribute to repress lineage-specific regulators, thus preventing the exit from the pluripotent state. OSN bind to and repress developmental-related genes in combination with repressive chromatin modifiers, such as SETDB1 and polycomb group (PcG) proteins, in both mouse and human ESCs (Boyer et al., 2006; Bracken et al., 2006; Lee et al., 2006; Young, 2011). Consequently, the loss of OSN-mediated repression rapidly leads to induction of developmental genes and to lineage commitment (Bernstein et al., 2006; Mikkelsen et al., 2007; Pan et al., 2007; Zhao et al., 2007).

Similarly, MYC TFs do not maintain PSCs identity only by regulating cell cycle, metabolic genes and cell growth/proliferation, as discussed above, but also by inhibiting PSCs differentiation, as demonstrated by several lines of evidence (Figure 1, lower right panel). In 2010, Smith and colleagues demonstrated that the simultaneous double knock-out of both $m y c$ and mycn (dKO) in either mESCs or iPSCs results in their differentiation toward primitive endoderm (Smith et al., 2010). This was attributed to the MYC-mediated repression of GATA6, a master regulator of primitive endoderm lineage commitment (Fujikura et al., 2002). Importantly, re-expression of either $m y c$ or mycn in the dKO background was sufficient to restore pluripotency, suggesting that the two TFs act redundantly in repressing GATA6 in PSCs. In addition to GATA6, MYC was also found to bind HES1 and transcriptionally repress FOXA2 and SOX17, other important primitive endoderm markers, while, in another report, it was demonstrated to limit hematopoietic differentiation, by repressing lineage-specific transcriptional activators and differentiation markers (Smith et al., 2010; Varlakhanova et al., 2010). These evidences suggest a more broad activity of MYC in regulating the differentiation potential of PSCs. Accordingly, MYC acts coordinately with MIZ-1 in suppressing differentiation of hESCs, by targeting and repressing a broad range of developmental related genes, including HOX clusters. MYC-mediated repression is less characterized compared to its positive regulatory activity, nonetheless, it is known that MYC is able to bind to MIZ-1 targets and inhibit its transcriptional activation. In addition, the MYC/MIZ-1 complex acts as a repressor by also recruiting histone deacetylases (HDACs) and DNA methyltransferases (DNMTs), which promote gene silencing (Herkert and Eilers, 2010). In hESCs, $\sim 200$ genes are co-bound by MYC/MIZ-1 comprising HOX and genes involved in neural and muscle differentiation, and at least $36 \mathrm{HOX}$ genes were proven to be transcriptionally down-regulated upon MYC disruption (Varlakhanova et al., 2011). Importantly, the MYC/MIZ-1 co-bound developmental genes are enriched in H3K27me3 histone mark, suggesting a potential link between MYC and PcG in PSCs. In line with this hypothesis, genome wide analysis reveals that $\sim 10 \%$ of MYC targets in mESCs are shared with the PRC2 protein SUZ12, leading to modulation of HOX, ectoderm and neural development-related genes (Lin et al., 2009b). More recently, we aimed to discern the functional roles of MYC in sustaining PSCs identity, by comparing mESCs grown in their standard culture medium, containing leukemia inhibitory factor (LIF) and serum, with cells grown solely in MYC-dependency (Fagnocchi et al., 2016a). To this end, we used mESCs expressing a $\mathrm{MYC}^{\mathrm{T} 58 \mathrm{~A}}$-estrogen receptor (MYC-ER) fusion protein, activated by 4-hydroxytamoxifenm (OHT) (Cartwright et al., 2005; Fagnocchi et al., 2016a). Importantly, we found that MYC down-regulates developmental-related genes involved in multi-lineage commitment which are targeted by PRC2 and/or PRC1. Almost half of total genes down-regulated by MYC in mESCs correlate with genes repressed by PRC2, and, for a subset of those genes (such as Dkk1, Sfrp1, Sfrp5, and Apcdd1) we demonstrated the direct role of MYC in recruiting the PRC2 complex on their promoters to mediate their transcriptional repression. Both MYC and MYCN physically interacts with PRC2 in mESCs. Indeed, thanks to biochemical approaches, we demonstrated that MYC, together with MAX, interacts with the three core component of PRC2 (Eed, Ezh2, and Suz12) and the Aebp2 associated protein, through its conserved MBII motif located in N-terminal TAD. Functional analysis revealed that the MYC/PRC2-induced inhibition of developmental pathways is required to maintain mESCs identity, as the knocking-down of either Eed or Ezh2, leads to spontaneous differentiation of MYC-dependent cells (Fagnocchi et al., 2016a). Altogether, these findings demonstrate the global role of MYC in modulating the differentiation potential of PSCs, in association with other TFs and chromatin players.

In addition to MYC-mediated direct modulation, it indirectly limits multi-lineage development of mESCs by transcriptionally up-regulating all genes coding for the PRC2 and associated factors (Neri et al., 2012). Furthermore, MYC is integrated in a regulatory circuitry including multiple miRNAs, which regulates expression of developmental-related genes in PSCs, as commented in the next section.

\section{MYC Integration with Non-coding RNAs Regulatory Circuits}

Non-coding RNAs (ncRNAs) are primary players in defining PSCs identity (Greve et al., 2013; Rosa and Brivanlou, 2013; Rosa and Ballarino, 2016). Among them, miRNAs are 20-base long, processed and single stranded transcripts, which recognize mRNAs by base pairing of a short "seed" sequence at their 5 ' end, thus leading to translational inhibition or degradation of their targets (Fabian and Sonenberg, 2012). Evidence for their role in pluripotency was first derived from mESCs lacking either Dicer or Dgcr8, two key factors in miRNAs maturation. Dicer- or Dgcr8-deficient mESCs are viable, but greatly impaired in cell cycle, proliferation and unable to properly differentiate (Kanellopoulou et al., 2005; Murchison et al., 2005; Wang et al., 2007). A specific family of miRNAs, sharing the same AAGUGC seed sequence, are conserved and majorly expressed among PSCs, the so called ESC-specific cell-cycle regulating (ESCC) miRNAs, which, together with ESCC-like miRNAs (shifted by one base), comprise up to the $60 \%$ of all the miRNA population 
in PSCs. This family includes the clusters miR-290-295 and miR17-92b in mESCs and miR-302-367 in mEpiSCs and hESCs, which, with exception of miR-17-92b, are not expressed in somatic cells. Conversely, the let-7 family of miRNAs is posttransciptionally repressed by the RNA binding protein LIN28, which is specifically expressed in PSC and down-regulated upon differentiation. (Greve et al., 2013; Rosa and Brivanlou, 2013). Both families of miRNAs play a central function in regulation of PSCs identity, underlined by the fact that their specific expression is controlled by the core TRN and they integrate with the OSN regulatory circuitry (Barroso-Deljesus et al., 2008; Card et al., 2008; Marson et al., 2008). In addition, ESCC influence PSCs by regulating their cell cycle, proliferation and differentiation potential.

Long (> 200 nucleotides) non-coding RNAs (lncRNAs) resemble protein-coding mRNAs and are usually spliced, polyadenylated and possess a $5^{\prime}$ cap. They can either act as antisense transcripts, modulate the activity of chromatin modifiers or serve as "sponges" for miRNAs, thus affecting their activity (Guttman and Rinn, 2012). The signature of both mouse and human ESCs have been deeply investigated, identifying ESC-specific lncRNAs, which are partly targets of the core TFs and whose levels decrease upon differentiation. Accordingly, their down-regulation results in reduction of proliferation and pluripotency markers expression, in parallel with induction of lineage specific genes and differentiation (Dinger et al., 2008; Guttman et al., 2009, 2010, 2011; Loewer et al., 2010; Sheik Mohamed et al., 2010; Ng et al., 2012).

As mentioned in the previous sections, the role of MYC in maintaining the PSC state is greatly interconnected with regulation of ncRNAs (Figure 1, lower left panel). MYC modulates both the counteracting ESCC and let-7 families of miRNAs in PSCs. The ESCC miRNAs were defined with the discovery that the miR-290-295 cluster was able to rescue the Dgcr8 ${ }^{-/-}$-induced defects on cell cycle and proliferation in mESCs. The miR-290-295 favors the rapid transition from G1 to $S$ phases and the peculiar cell cycle structure of PSCs, by regulating the Cdk2-cyclin E complex. Importantly, miR-290295 acts downstream of MYC, which binds their promoters, and is also involved in establishment of iPSCs, being able to replace MYC in the reprogramming of mouse fibroblasts (Wang et al., 2008; Judson et al., 2009). On the other hand, the let-7 family promotes differentiation and MYC, by transcriptionally inducing the let-7 repressor LIN28, together with OSN, limits its expression, thus supporting the PSCs state. Additionally, in lymphoma cells, MYC directly binds let-7 and represses it, while, in turn, mature let-7 inhibits MYC expression, suggesting that these two factors are involved in a doublenegative feedback regulatory loop (Chang et al., 2008, 2009; Marson et al., 2008; Melton et al., 2010; Zhong et al., 2010). Importantly, the LIN28/let-7 axis has been also demonstrated to be a central regulator of PSCs metabolism, in particular as far as mitochondrial respiration is concerned (Shyh-Chang and Daley, 2013; Psathas and Thomas-Tikhonenko, 2014), suggesting MYC implication in the regulation of the Oxphos metabolism critical to ESCs (Wang et al., 2009a; Zhang et al., 2011; Carbognin et al., 2016). Furthermore, MYC induces the miR-17-92 cluster in mESCs, which supports cell cycle progression by the inhibition of controllers such as p21, cyclin $\mathrm{D} 1$ and RB2. Accordingly, in MYC/MYCN dKO mESCs, the miR-17-92 cluster is down-regulated and cells differentiate and re-structure their cell cycle (Smith and Dalton, 2010; Smith et al., 2010). MYC also directly activates miR-141, miR-200, miR-338, and miR429, which repress differentiation pathways (Lin et al., 2009a; Psathas and Thomas-Tikhonenko, 2014). Importantly, up-regulation or inhibition of those classes of miRNAs result in reduction or enhancement of differentiation of mESCs, respectively, thus showing the functional importance of this $\mathrm{MYC} / \mathrm{miRNAs}$ integration in regulating the differentiation potential of PSCs (Lin et al., 2009a). More recently, instead, MYC has been demonstrated to indirectly limit the expression of miR24-3p/miR-24-2-5p, which inhibit OSN and MYC itself, acting as anti-pluripotent miRNAs in mESCs. MYC and OSN activate the protein arginine methyltransferase 7 (PRMT7), which, in turn limits miR-24-3p/miR-24-2-5p expression (Lee et al., 2016). Interestingly, MYC induces a stem-cell like miRNA signature in aggressive hepatoblastomas, characterized by repression of miR-100/let-7a-2/miR-125b-1 and activation of miR-371 (part of the human homolog of murine miR-290-295), suggesting that MYC-mediated regulation of miRNAs in PSCs is partly shared with cancer cells and functionally relevant for tumorigenesis. In support of this hypothesis, reversal of the MYC-driven miRNA signature results into smaller tumor formation in mice (Chang et al., 2008; Cairo et al., 2010). Finally, MYC has also been implicated in the regulation of lncRNAs controlling pluripotency and differentiation, either by directly binding their promoters or by modulating their expression in collaboration with Dicer and miRNAs, suggesting an even broader role of MYC in controlling ncRNA in PSCs (Guttman et al., 2011; Zheng et al., 2014).

\section{MYC and the Epigenetic State of PSCs}

PSCs are endowed with unique chromatin and epigenetic organization which allow their genome to respond to two opposing needs: on one hand, it must be plastic to be ready to enter developmental pathways; on the other side, it must retain a cellular memory that specifies the PSCs state. To this end, the PSC chromatin is highly dynamic and accessible, when compared to committed cells, with large regions of transcribed euchromatin and restricted PcG-repressed and heterochromatic domains, marked with H3K27me3 and/or H3K9me3 (Brenner et al., 2005; Meshorer and Misteli, 2006; Efroni et al., 2008; Gaspar-Maia et al., 2011; Zhu et al., 2013; Tee and Reinberg, 2014). In addition, the most distinctive epigenetic feature of PSCs is represented by the presence of bivalent domains, carrying both activating $\mathrm{H} 3 \mathrm{~K} 4 \mathrm{me} 3$ and repressing $\mathrm{H} 3 \mathrm{~K} 27 \mathrm{me} 3$ histone modifications and marking poised developmental-related genes, ready to be activated in response to pro-differentiative stimuli (Bernstein et al., 2006; Boyer et al., 2006; Lee et al., 2006; Mikkelsen et al., 2007; Pan et al., 2007; Zhao et al., 2007).

MYC has been described to influence the global cellular chromatin structure and to favor widespread active euchromatin, by promoting hyperacetylation and modulating both $\mathrm{H} 3 \mathrm{~K} 4 \mathrm{me} 3$ and $\mathrm{H} 3 \mathrm{~K} 9 \mathrm{ac}$, thus suggesting its role in defining the peculiar chromatin state of PSCs (Knoepfler et al., 2006; Frye et al., 
2007; Cotterman et al., 2008) (Figure 1, lower central panel). In line with this idea, MYC null mESCs show a global epigenetic remodeling, with a decrease of $\sim 70 \%$ of the active histone mark H3K4me3, which significantly overlap with MYC binding sites (Lin et al., 2009b). Mechanistically, MYC affects the chromatin structure and the epigenetic landscapes in multiple ways. First of all, it may transcriptionally modulate various chromatin regulators. Indeed, components of the $\mathrm{PRC} 1 / 2$, of histone acethyl- and methyltransferases complexes and of the Swi/Snf remodeling factors were identified among MYC targets in mESCs (Kidder et al., 2008; Kim et al., 2008; Neri et al., 2012; Krepelova et al., 2014). Secondly, MYC is well-documented to interact with and recruit onto the chromatin several players implicated in chromatin modifications and dynamics (Hann, 2014; Tu et al., 2015). In particular, MYC interacts with various histone acethyltransferase (HAT) complexes on their common targets, suggesting its role in modulating the global histone $\mathrm{H} 3$ and $\mathrm{H} 4$ acetylation state of PSCs (Mcmahon et al., 2000; Frank et al., 2001, 2003; Fazzio et al., 2008; Lin et al., 2009b; Kim et al., 2010). More recently, MYC has been found to co-localize on active genes with two histone demethylases (HDMs), namely $\mathrm{Kdm} 4 \mathrm{~b} / \mathrm{c}$, required for mESCs self-renewal, suggesting MYC implication also in the regulation of the histone methylation state of PSCs (Das et al., 2014). Furthermore, MYC may regulate transcriptional repression in PSCs by physically interacting with epigenetic regulators, such as $\mathrm{Hdac1} / 3, \operatorname{Sin} 3 \mathrm{~A} / \mathrm{B}$ and Lsd1 (Kdm1a), which are part of chromatin repressive complexes affecting both histone acetylation and demethylation. (Liang et al., 2008; Wang et al., 2009b; Smith et al., 2011; Hu and Wade, 2012; Mcdonel et al., 2012; Amente et al., 2013; Garcia-Sanz et al., 2014). In line with these evidences, in mESCs grown in MYC-dependency, MYC interacts with PRC2 and this interaction is functionally relevant in affecting the epigenome and the identity of mESCs. Indeed, we demonstrated a global increment of both Suz12 binding and $\mathrm{H} 3 \mathrm{~K} 27 \mathrm{me} 3$ deposition on promoters of bivalent genes, compared to ESCs grown in presence of LIF. In addition, MYC is able to directly recruit PRC2 on a subset of these bivalent promoters, thus augmenting $\mathrm{H} 3 \mathrm{~K} 27 \mathrm{me} 3$ and repressing gene expression. Accordingly, impaired expression of either Eed or Ezh2 is not compatible with maintenance of MYC-dependent mESCs (Fagnocchi et al., 2016a).

\section{MYC Modulation of Signaling Pathways}

The TRN of PSCs is continuously targeted by downstream effectors of environmental signaling pathways, which, therefore, play a pivotal role in determining different pluripotent states. As a consequence, propagation of diverse PSCs strictly relies on well-defined growth conditions. Mouse ESCs were first derived on mitotically inactive embryonic fibroblasts as feeders and in presence of serum (Evans and Kaufman, 1981; Martin, 1981). Thereafter, LIF and the bone morphogenetic protein 4 (BMP4) were identified as key ingredients to propagate mESCs in feederand serum-free conditions, thanks to their ability to activate the Janus kinase-signal transducer and activator of transcription 3 (JAK/STAT3) pathway and repress developmental processes through the SMAD/IDs cascade, respectively (Smith et al., 1988; Williams et al., 1988; Ying et al., 2003). Nonetheless, LIF/serum medium is commonly used as standard growing condition for mESCs. Consequently, several other defined culturing media, based on the utilization of chemical inhibitors, were developed to propagate mESCs in a more "naïve" state of pluripotency (also known as "ground state"), thus being more similar to early pre-implantation PSCs of the ICM (Weinberger et al., 2016). Among them, the two inhibitors (2i)/LIF medium relies on the chemical repression of the MAPK/ERK kinases signaling, achieved with PD0325901 (PD03), and concomitant activation of the WNT pathway, through the use of CHIR99021 (CHIR), which inhibits GSK3 $\beta$, thus stabilizing $\beta$-catenin, which ultimately counteracts Tcf3 pro-differentiative activity in the nucleus (Cole et al., 2008; Ying et al., 2008). Activation of the MAPK/ERK cascade drives the transition toward primed pluripotency and, therefore, both primed hESCs and murine EpiSCs are cultured in presence of basic fibroblast growth factor (FGF2), which activates MAPK/ERK, and Activin A, which reinforces the transforming growth factor- $\beta$ (TGF $\beta$ ) signaling (Thomson et al., 1998; Brons et al., 2007; Tesar et al., 2007). More recently, several reports identified culture conditions to propagate naïve hESCs, suggesting that this pluripotent state, similarly to its murine counterpart, relies on ablation of the MAPK/ERK pathway, activation of the BMP4, LIF, and WNT signaling cascades and low activation of Activin A/TGF $\beta 1$ (Cartwright et al., 2005; Gafni et al., 2013; Theunissen et al., 2014; Ware et al., 2014). Finally, to support the importance of LIF, BMP4, and WNT signaling pathways in determining naïve PSC identity, downstream effectors such as STAT3, SMAD1, and TCF3, respectively, are hard-wired into the core TRN (Chen et al., 2008; Cole et al., 2008; Ho et al., 2011).

MYC was first connected to the signaling pathways of PSCs, when it was discovered to be a downstream target of the LIF/Stat3 cascade in mESCs (Cartwright et al., 2005) (Figure 1, upper right panel). Upon LIF withdrawal, MYC levels decrease, due to both lack of transcriptional activation and post-translational GSK3 $\beta$ dependent phosphorylation of threonine 58 (T58). Importantly, sustained MYC activity, through activation of a MYC-ER fusion protein, is able to circumvent LIF-dependency of mESCs, suggesting that the LIF signaling importance for the pluripotent state is, at least partially, due to MYC functions. Accordingly, expression of a MYC dominant negative mutant leads to loss of self-renewal and differentiation (Cartwright et al., 2005). Consequently, MYC was also found to be involved in limiting the MAPK/ERK signaling, thus sustaining pluripotency of mESCs (Chappell et al., 2013). While ERK is known to stabilize MYC protein, it has been shown that MYC and MAX transcriptionally activate the dual specific phosphatases 2 and 7 (DUSP2/7), which in turn bind and inactivate ERK1/2 through its dephosphorylation, leading to attenuation of the MAPK/ERK activity. In accordance, loss of MYC leads to down-regulation of DUSP2/7, stimulation of the MAPK/ERK pathway and differentiation of mESCs (Sears et al., 2000; Chappell et al., 2013). More recently, we demonstrated that MYC also sustains the WNT pathway in mESCs and that this is required for MYCmediated maintenance of both self-renewal and pluripotency (Fagnocchi et al., 2016a) (Figure 2A). Indeed, MYC leads to an accumulation of nuclear $\beta$-catenin, while $\mathrm{MYC/MYCN} \mathrm{dKO}$ 
A

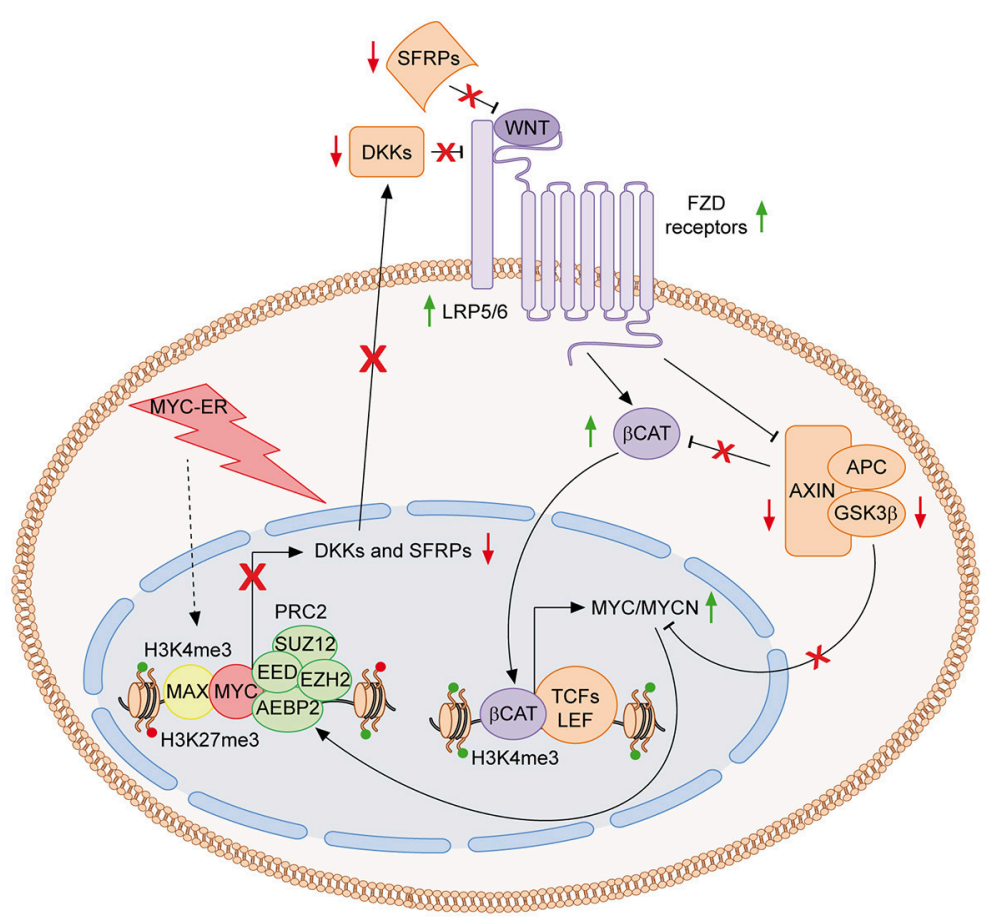

B

MYC-dependent mESCs

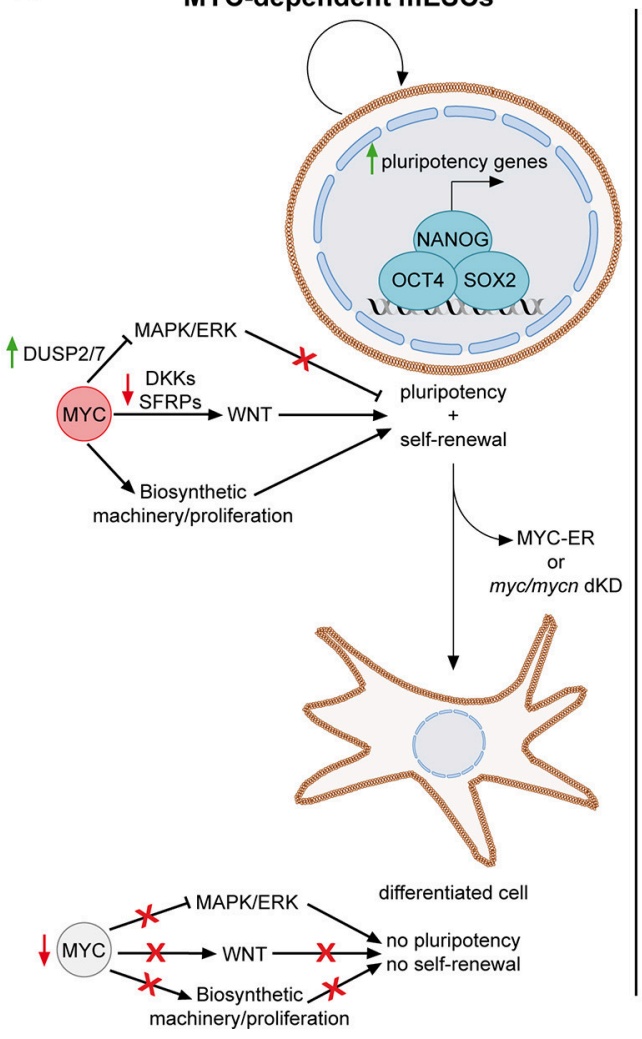

2i/LIF maintained mESCs

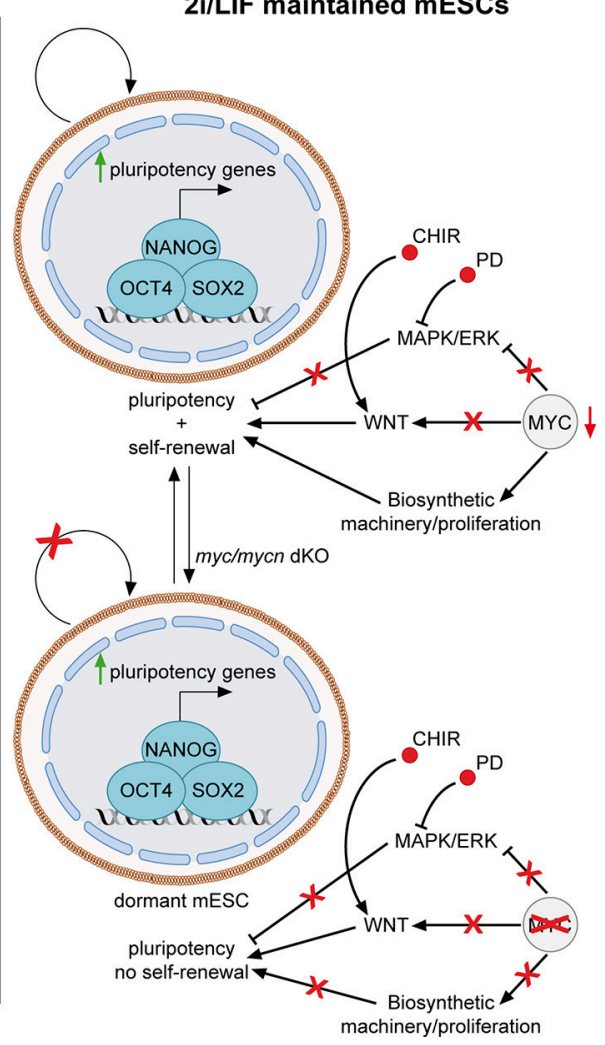

FIGURE 2 | The MYC-driven self-reinforcing loop in ESCs. (A) MYC-dependent ESCs are maintained in presence of OHT, which activate MYC-ER, finally leading to its nuclear localization. In the nucleus, MYC-ER stimulates a self-reinforcing positive feedback loop. Together with PRC2, MYC represses antagonist of the WNT pathway, such as DKK and SFRP family members, thus resulting in activation of the WNT pathway. Consequently, active $\beta$-catenin translocates into the nucleus, where, among its targets, it transcriptionally activates both myc and mycn. Endogenous MYC and MYCN, in turn, reinforce this mechanism by contributing to the repression of WNT antagonists. The feedback positive loop is also sustained by the fact that MYC mediates the inhibition of the destruction complex (AXIN, APC, 


\section{FIGURE 2 | Continued}

GSK3 $\beta$ ) function, resulting in reduction of GSK3 $\beta$-dependent degradation of both MYC/MYCN and $\beta$-catenin (Fagnocchi et al., 2016a). (B) Role of MYC in sustaining mESCs identity in MYC-dependent vs. 2i/LIF maintained cells. MYC-dependent cells rely on MYC for the concomitant down-regulation of MAPK/ERK and up-regulation of WNT pathways (Chappell et al., 2013; Fagnocchi et al., 2016a). In addition, it also sustains proliferation by inducing the biosynthetic machinery. Once MYC activity is lost, by either knocking down myc/mycn or by inactivating MYC-ER after short-term exposure to OHT, mESCs differentiate spontaneously as both the proliferation and the maintenance of pluripotency gene expression are affected (Cartwright et al., 2005; Fagnocchi et al., 2016a). On the contrary, in 2i/LIF cultured cells, chemical inhibitors bypass the role of MYC in modulating signaling pathways. Indeed, CHIR and PD activate and inhibit WNT and MAPK/ERK pathways, respectively (Cole et al., 2008; Ying et al., 2008). Accordingly, MYC is less expressed in 2i/LIF mESCs (Marks et al., 2012). Nonetheless, MYC still have a key function in 2i/LIF medium, as its deletion leads to impairment of the biosynthetic machinery and entrance of ESCs in a reversible dormant state (Scognamiglio et al., 2016). Concomitantly, the pluripotency is not affected as chemical inhibitors still modulate signaling to the core TRN even in the absence of MYC. Solid green and red arrows indicate high or low expression on nearby genes, respectively. Solid black arrows and flat lines indicate activation or repression, respectively. Red crosses indicate inhibition of related functions.

mESCs show reduced amount of active $\beta$-catenin, respect to wild type cells. Importantly, WNT pathway activation is fundamental for MYC-mediated maintenance of mESCs, as either knocking-down $\beta$-catenin or down-modulation of WNT signaling with soluble inhibitors Dkk1 and Srfp1, result in loss of stemness and spontaneous differentiation. Mechanistically, MYC activates WNT signaling by transcriptionally activating receptors and co-receptors (such as Fzd2, 3, and 7 and Lrp5), while repressing antagonists of the pathway (such as Dkk and Sfrp inhibitors family members), by directly recruiting PRC2 on their promoters (Figure 2A). Of importance, endogenous $m y c$ and mycn genes are targets of nuclear $\beta$-catenin and MYC-mediated activation of the WNT pathway leads to their transcriptional up-regulation, in a positive self-reinforcing regulatory loop (Figure 2A) (Fagnocchi et al., 2016a).

Alltogether, these evidences collectively indicate that MYC sustains PSC identity by inducing the WNT-pathway, while limiting the MAPK/ERK signaling, resembling the activity of chemical inhibitors of the 2i/LIF culturing medium (Figure 2B). In accordance with this finding, in $2 \mathrm{i} / \mathrm{LIF}$ mESCs the level of MYC expression is lower compared to LIF/serum maintained cells (Marks et al., 2012), suggesting that PD03 and CHIR bypass the requirement of MYC to modulate signaling pathways relevant for maintenance of pluripotency. While the chemicals in $2 \mathrm{i} / \mathrm{LIF}$ medium may render "ground state" mESCs partly independent to MYC for their maintenance, they still require its activity for their biosynthetic homeostasis. In fact, recent findings show that pharmacological inhibition of MYC activity or MYC/MYCN concomitant deletion in mESCs cultured in 2i/LIF, results in reduced RNA processing, ribosome biogenesis, protein synthesis and, ultimately, arrest of proliferation and entering in a dormant state, remindful of diapause balstocysts (Scognamiglio et al., 2016). These conclusions suggest that MYC-mediated control of the biosynthetic machinery in $2 \mathrm{i} /$ LIF cultured mESCs is uncoupled from regulation of their pluripotency and rather mostly implicated in their self-renewal potential (Figure 2B).

\section{MYC in the Reprogramming of Somatic Cells}

Despite no data are available to prove a role for MYC in establishing PSCs in vivo, the major evidence underlying its function in the induction of the pluripotent state is its wellknown role in reprogramming of somatic cells. MYC is one of the four transcription factors, together with OCT4, SOX2 and
KLF4 (OSKM), initially identified by Shinya Yamanaka's lab as sufficient to reprogram differentiated cells to iPSCs, both in mice and humans (Takahashi and Yamanaka, 2006; Takahashi et al., 2007). Since then, many different variations from the OSKM cocktail have been used to improve the derivation of iPSCs (Buganim et al., 2013; Theunissen and Jaenisch, 2014; Takahashi and Yamanaka, 2016), nonetheless the reprogramming process in absence of MYC is generally less efficient, both in terms of the number of iPSCs and the time required to reach full reprogrammed state (Nakagawa et al., 2008; Wernig et al., 2008). Moreover, among the OSKM factors, MYC promotes the most ESC-like transcriptional signature in fibroblasts, when expressed alone (Sridharan et al., 2009).

Reprogramming is a multi-step event, throughout which MYC exerts its function since the early stages (Mikkelsen et al., 2008; Sridharan et al., 2009; Soufi et al., 2012). In fact, MYC has been proposed to mediate early global epigenetic changes, required for the formation of euchromatin. Accordingly, two HDAC inhibitors, the valproic acid (VPA) and trichostatin A (TSA), enable reprogramming of both human and murine fibroblasts in absence of MYC, indicating its role in controlling global histone acetylation during generation of iPSCs (Huangfu et al., 2008; Araki et al., 2011). These global epigenetic changes are reflected in remodeling of gene expression patterns: MYC enhances early reprogramming by repressing fibroblast specific genes more efficiently than OCT4, SOX2, and KLF4 (OSK), while inducing a PSC-like gene expression profile (Mikkelsen et al., 2008; Sridharan et al., 2009). Of importance, MYC binds to enhancers of pluripotency-related genes in early phases of de-differentiation and there it increases the OSK engagement with chromatin and its activating function. Nonetheless, it is noteworthy that MYC cannot act as a "pioneer factor" and requires previous binding of OSK to access the chromatin (Soufi et al., 2012).

Several factors can replace MYC function during reprogramming, including metabolic modulators, miRNAs and other pluripotent TFs, indicating that those mechanisms by which MYC maintains PSCs, might also be relevant for establishment of iPSCs (Yu et al., 2007; Judson et al., 2009; Choi et al., 2011; Psathas and Thomas-Tikhonenko, 2014; Cao et al., 2015; Ryall et al., 2015). In addition, the role of MYC in modulating the cell cycle might be relevant for later stages of reprogramming, as the typical cell cycle structure of PSCs is not present in partially reprogrammed cells (Singh and Dalton, 2009). 
A

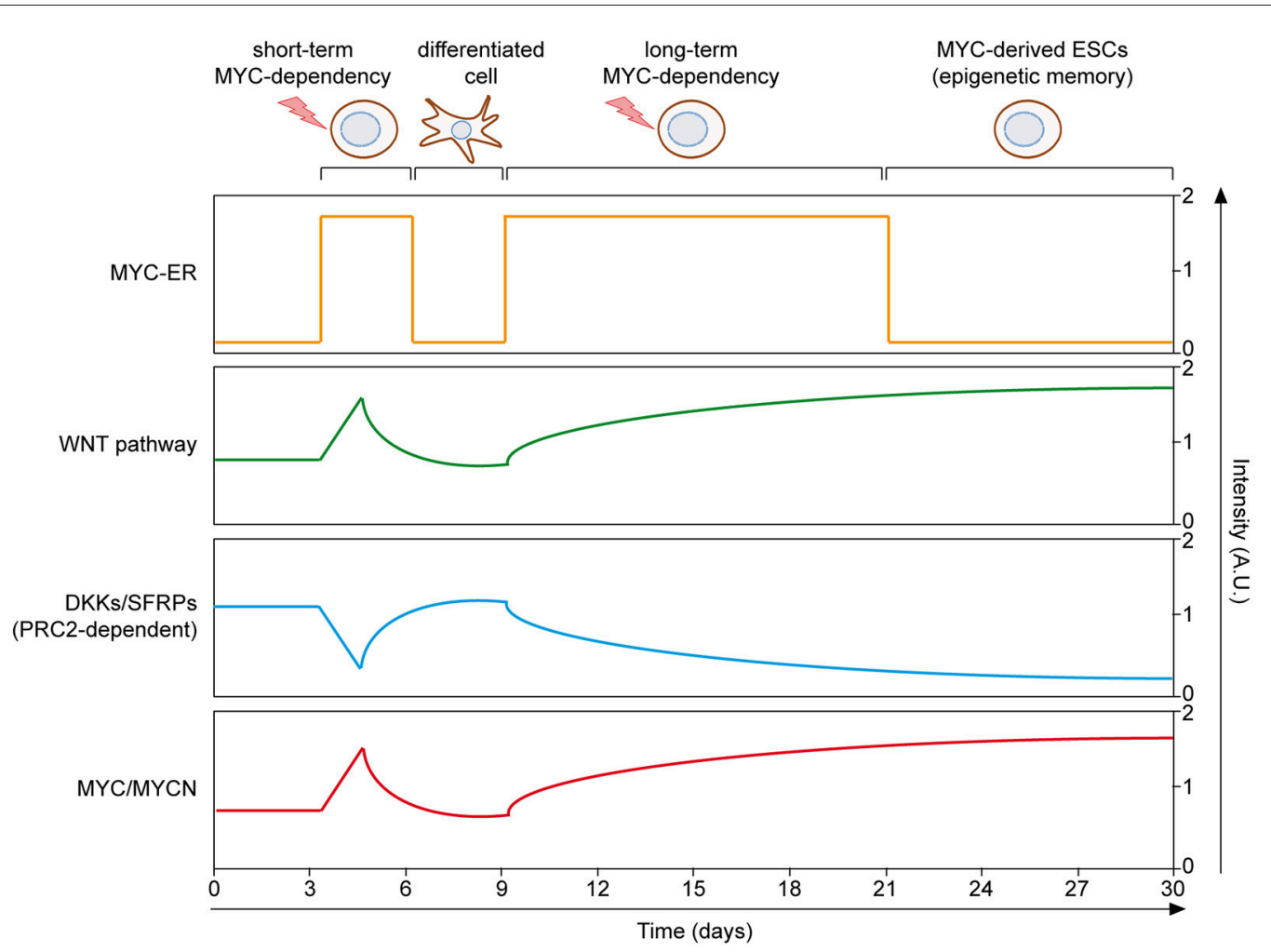

B

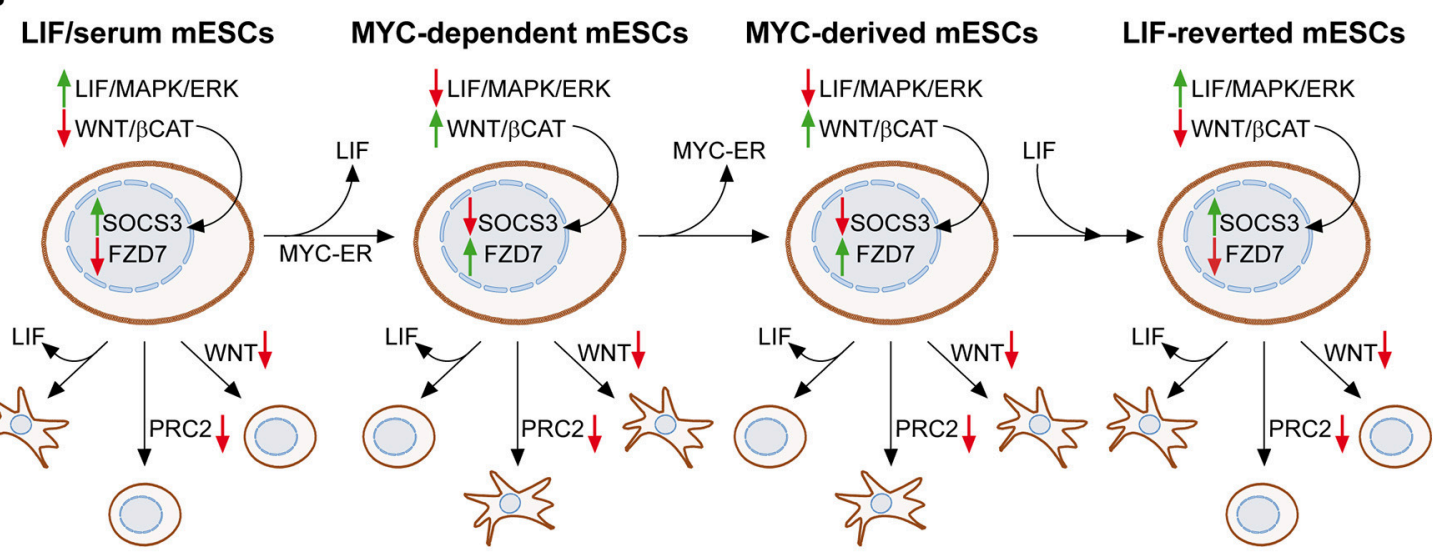

FIGURE 3 | MYC induces and epigenetic memory mechanism in ESCs. (A) Mouse ESCs can be maintained upon LIF withdrawal, providing activation of MYC-ER, which leads to WNT pathway reinforcement, through PRC2-mediated repression of its antagonist, and induction of endogenous MYC and MYCN. If MYC-ER remains activate for short term (e.g., 3-6 days), mESCs differentiate spontaneously once it is inactivated. On the contrary, long term activation of MYC-ER (at least 12 days) leads to the stabilization of WNT reinforcement and concomitant induction of MYC/MYCN, even in the absence of the original stimulus (OHT), thanks to a self-reinforcing loop. This epigenetic memory mechanism permits the maintenance of MYC-derived mESCs in absence of both LIF and MYC-ER activation (Fagnocchi et al., 2016a). (B) The epigenetic memory of MYC-derived mESCs permits their reversion to a LIF-dependent state of pluripotency. LIF/serum maintained mESCs are dependent on LIF/JAK/STAT cascade; hence LIF withdrawal leads to their differentiation. On the contrary, inhibition of both PRC2 activity and WNT pathway do not affect their pluripotent state. Both MYC-dependent and MYC-derived mESCs are, instead, insensitive to LIF withdrawal, but rather strictly dependent on the MYC/PRC2-mediated activation of WNT pathway. Importantly, culturing MYC-derived mESCs in LIF/serum medium reverts them back to a LIF-dependent but PRC2/WNT-independent pluripotent state, underlying the epigenetic nature of the memory mechanism which permits their derivation. Accordingly, the expression of downstream targets of both LIF and WNT pathways (SOCS3 and FZD7) is epigenetically controlled and switched between the different pluripotent states described (Fagnocchi et al., 2016a). Solid green and red arrows indicate high or low expression on nearby genes/functions, respectively. 
Importantly, the clinical applications of iPSCs, are partly hindered by the fact that MYC activation leads to oncogenic transformation and animals derived from iPSCs induced by OSKM frequently develop tumors (Okita et al., 2007). While poor reprogramming is achieved without MYC (Nakagawa et al., 2008; Wernig et al., 2008), the possibility to derive iPSCs with MYCL, which posses less transformation capability, and, above all, with transformation-defective MYC mutants, it is worth further investigation to obtain clinically safe reprogrammed pluripotent cells with high efficiency (Nakagawa et al., 2008, 2010).

\section{MYC and Epigenetic Memory}

The epigenetic memory can be defined as "a heritable change in gene expression or behavior, that is induced by a previous developmental or environmental stimulus and cannot be explained by changes in the DNA sequence" (D'urso and Brickner, 2014). During development, cells progressively reduce their differentiation potential and acquire a committed cell identity, in response to specific stimuli, which will be then maintained long after the stimulus is passed (Ringrose and Paro, 2004; Bonasio et al., 2010). This phenotypic stability of differentiated cells relies on mechanisms which ensure the transmission of epigenetic and, consequently, transcriptional patterns. Accordingly, efficient reprogramming of committed cells toward pluripotency requires the erasure of the existing somatic epigenetic memory, which constitutes well-known barriers to formation of iPSCs (Mikkelsen et al., 2008; Pasque et al., 2012; Chen et al., 2013; Gaspar-Maia et al., 2013; Sridharan et al., 2013; Nashun et al., 2015). Mechanistically, epigenetic inheritance can be achieved by either self-propagating transacting regulatory factors, maintained by feedback loops and TF networks, or by cis-acting epigenetic signatures, such as DNA methylation or histone modifications, which must be maintained or re-established during and after cell division, respectively (Bonasio et al., 2010; Moazed, 2011; Wang and Higgins, 2013). Importantly, recent evidences indicate that epigenetic memory is also maintained in ESCs, even though with different mechanisms respect to somatic cells. Hence, the pluripotent state is characterized by a highly stable epigenome (Shipony et al., 2014).

We recently described a MYC-driven epigenetic memory mechanism, which is able to maintain mESC identity (Fagnocchi et al., 2016a). As mentioned above, MYC-dependent mESCs rely on the activation of the WNT pathway to support their stemness, which in turn induces expression of both endogenous $m y c$ and mycn genes, establishing a positive feedback loop (Figure 2A). Importantly, mESCs maintained for long-term in MYC-dependency retain their identity, differentiation potential and pluripotency, even after deactivation of MYC-ER. On the contrary, mESCs which experienced short-term activation of MYC-ER are not able to maintain the pluripotent state upon MYC-ER deactivation and differentiate spontaneously. These evidences indicate that the MYC-driven self-reinforcing circuit, installed during MYC-dependency, is able to sustain PSCs in the absence of the instructing stimulus. In accordance, mESCs derived after MYC-ER deactivation (MYC-derived) possess a transcriptional program conserved with MYC-dependent cells and show activation of the WNT pathway, which is achieved by the endogenous MYC proteins that recruit PRC2 on WNT antagonists (Figure 3A). By definition, epigenetic regulatory mechanisms must be reversible, as they are not dictated by changes in DNA (Bonasio et al., 2010). In agreement with this, MYC-derived cells can be reprogrammed to a LIF-dependent state of pluripotency. Indeed, MYC-derived mESCs, as their parental MYC-maintained counterpart, are strictly dependent on WNT pathway activation and the PRC2 activity, while mESCs cultured in LIF/serum only depend on the JAK/STAT3 signaling (Figure 3B). By culturing MYC-derived cells in $\mathrm{LIF} /$ serum containing medium, they undergo a reprogramming process which render them LIF-dependent but WNT- and PRC2-independent. Of importance, this is accompanied by an epigenetic reprogramming in which WNT pathway related genes (e.g., Fzd7) switch from an active state, marked by H3K4me3 deposition on their promoter, to transcriptional repression, underlined by gaining of the $\mathrm{H} 3 \mathrm{~K} 27 \mathrm{me} 3$ repressive mark. Vice versa, downstream effectors of the LIF/JAK/STAT3 cascade (e.g., SOCS3) re-acquire transcriptional activation, after having been repressed in both MYC-dependent and MYC-derived cells (Figure 3B). Altogether, these evidences demonstrate that MYC is able to induce a reversible epigenetic memory, which is sufficient to sustain PSCs.

\section{CONCLUSIONS AND IMPLICATIONS}

Since MYC was first implicated in maintaining mESCs more than 10 years ago (Cartwright et al., 2005), its central role in integrating complex regulatory networks in PSCs has been tremendously reinforced and deepened. Its ability to bind specific targets and to possibly invade less specific genomic regions (Lin et al., 2012; Nie et al., 2012; Sabo et al., 2014; Walz et al., 2014), together with its plethora of interactions with other TFs and chromatin players (Smith et al., 2011; Tu et al., 2015), renders MYC a central hub involved in many aspects of the PSC regulation. For the same reason, the therapeutic implications of unraveling the MYC-mediated molecular mechanisms, which induce and maintain the pluripotent state, are self-evident.

Immediately after their first derivation (Takahashi et al., 2007), human iPSCs were generated from patients affected from a variety of pathologies (Dimos et al., 2008; Park et al., 2008). These patients-derived iPSCs hold the potential to generate disease models, which overcome the limits imposed by using other mammal models, such as the differences at the genomic level, in embryonic development and organ functions. Both human ESCs, either carrying spontaneous chromosomal aberrations or genetically engineered, and iPSCs from patients are now used as disease models, whose applications range from identification of the pathological molecular mechanisms, to drug discovery and toxicity testing (Zeltner and Studer, 2015; Avior et al., 2016). Furthermore, the use of patient-specific PSCs holds promises to move medical research and therapies toward more personalized approaches. Accordingly, hESCs/iPSCs may be eventually used in autologous cell replacement therapies and PSC-derivatives are now being evaluated in ongoing clinical trials for their 
safety and therapeutic benefits (Trounson and Dewitt, 2016). Finally, iPSCs can also be used as models for tumorigenesis (Kim and Zaret, 2015; Laplane et al., 2015). Indeed, human cells from a variety of cancers have been reprogrammed to iPSCs, in which the pluripotency state can partially suppress cancer features, by restoring the differentiation potential while reducing tumorigenicity. Nonetheless, these cancer-derived iPSCs can reacquire the aggressive phenotype, once differentiated toward the tissue of origin, therefore representing a powerful tool to study early steps of oncogenesis, its progression, the markers and pathways involved and the response to therapeutics (Kim and Zaret, 2015; Laplane et al., 2015). In this regard, the role of MYC in controlling the regulatory networks of PSCs is particularly important as it is found up-regulated in up to the $70 \%$ of all human malignancies and, as commented in the previous sections, some of its regulated functions are shared between cancer and PSC, opening the possibility for therapeutic targeting (Dang, 2012; Ciriello et al., 2013; Gabay et al., 2014).

\section{REFERENCES}

Amente, S., Lania, L., and Majello, B. (2013). The histone LSD1 demethylase in stemness and cancer transcription programs. Biochim. Biophys. Acta 1829, 981-986. doi: 10.1016/j.bbagrm.2013.05.002

Araki, R., Hoki, Y., Uda, M., Nakamura, M., Jincho, Y., Tamura, C., et al. (2011). Crucial role of c-Myc in the generation of induced pluripotent stem cells. Stem Cells 29, 1362-1370. doi: 10.1002/stem.685

Avilion, A. A., Nicolis, S. K., Pevny, L. H., Perez, L., Vivian, N., and Lovell-Badge, R. (2003). Multipotent cell lineages in early mouse development depend on SOX2 function. Genes Dev. 17, 126-140. doi: 10.1101/gad.224503

Avior, Y., Sagi, I., and Benvenisty, N. (2016). Pluripotent stem cells in disease modelling and drug discovery. Nat. Rev. Mol. Cell Biol. 17, 170-182. doi: $10.1038 / \mathrm{nrm} .2015 .27$

Barrett, J., Birrer, M. J., Kato, G. J., Dosaka-Akita, H., and Dang, C. V. (1992). Activation domains of L-Myc and c-Myc determine their transforming potencies in rat embryo cells. Mol. Cell. Biol. 12, 3130-3137. doi: 10.1128/MCB.12.7.3130

Barroso-Deljesus, A., Romero-Lopez, C., Lucena-Aguilar, G., Melen, G. J., Sanchez, L., Ligero, G., et al. (2008). Embryonic stem cell-specific miR302-367 cluster: human gene structure and functional characterization of its core promoter. Mol. Cell. Biol. 28, 6609-6619. doi: 10.1128/MCB.00398-08

Baudino, T. A., Mckay, C., Pendeville-Samain, H., Nilsson, J. A., Maclean, K. H., White, E. L., et al. (2002). c-Myc is essential for vasculogenesis and angiogenesis during development and tumor progression. Genes Dev. 16, 2530-2543. doi: 10.1101/gad.1024602

Bellin, M., Marchetto, M. C., Gage, F. H., and Mummery, C. L. (2012). Induced pluripotent stem cells: the new patient? Nat. Rev. Mol. Cell Biol. 13, 713-726. doi: $10.1038 / \mathrm{nrm} 3448$

Bernstein, B. E., Mikkelsen, T. S., Xie, X., Kamal, M., Huebert, D. J., Cuff, J., et al. (2006). A bivalent chromatin structure marks key developmental genes in embryonic stem cells. Cell 125, 315-326. doi: 10.1016/j.cell.2006.02.041

Blackwell, T. K., Huang, J., Ma, A., Kretzner, L., Alt, F. W., Eisenman, R. N., et al. (1993). Binding of myc proteins to canonical and noncanonical DNA sequences. Mol. Cell. Biol. 13, 5216-5224. doi: 10.1128/MCB.13.9.5216

Blackwell, T. K., Kretzner, L., Blackwood, E. M., Eisenman, R. N., and Weintraub, H. (1990). Sequence-specific DNA binding by the c-Myc protein. Science 250, 1149-1151. doi: 10.1126/science.2251503

Blackwood, E. M., and Eisenman, R. N. (1991). Max: a helix-loop-helix zipper protein that forms a sequence-specific DNA-binding complex with Myc. Science 251, 1211-1217. doi: 10.1126/science.2006410

Bonasio, R., Tu, S., and Reinberg, D. (2010). Molecular signals of epigenetic states. Science 330, 612-616. doi: 10.1126/science.1191078
While the feasibility of generating PSC-based models and deriving cells for regenerative medicine have been often reported, much additional work will be required to evaluate the impact of those applications in treating multiple diseases.

\section{AUTHOR CONTRIBUTIONS}

LF and AZ discussed the subject and wrote the manuscript.

\section{ACKNOWLEDGMENTS}

We would like to thank Vittoria Poli and Alessandra Fasciani for critical reading of the manuscript. Work in AZ laboratory is supported by grants from the Italian health ministry (GR2010-11 2319033; GR-2011-02351172), by Epigenomics Flagship Project (EPIGEN), and CARIPLO foundation (2014-0915).

Boyer, L. A., Lee, T. I., Cole, M. F., Johnstone, S. E., Levine, S. S., Zucker, J. P., et al. (2005). Core transcriptional regulatory circuitry in human embryonic stem cells. Cell 122, 947-956. doi: 10.1016/j.cell.2005.08.020

Boyer, L. A., Plath, K., Zeitlinger, J., Brambrink, T., Medeiros, L. A., Lee, T. I., et al. (2006). Polycomb complexes repress developmental regulators in murine embryonic stem cells. Nature 441, 349-353. doi: 10.1038/nature04733

Bracken, A. P., Dietrich, N., Pasini, D., Hansen, K. H., and Helin, K. (2006). Genome-wide mapping of Polycomb target genes unravels their roles in cell fate transitions. Genes Dev. 20, 1123-1136. doi: 10.1101/gad.381706

Brenner, C., Deplus, R., Didelot, C., Loriot, A., Vire, E., De Smet, C., et al. (2005). Myc represses transcription through recruitment of DNA methyltransferase corepressor. EMBO J. 24, 336-346. doi: 10.1038/sj.emboj.7600509

Bretones, G., Delgado, M. D., and Leon, J. (2015). Myc and cell cycle control. Biochim. Biophys. Acta 1849, 506-516. doi: 10.1016/j.bbagrm.2014.03.013

Brons, I. G., Smithers, L. E., Trotter, M. W., Rugg-Gunn, P., Sun, B., Chuva De Sousa Lopes, S. M., et al. (2007). Derivation of pluripotent epiblast stem cells from mammalian embryos. Nature 448, 191-195. doi: 10.1038/nature05950

Buganim, Y., Faddah, D. A., and Jaenisch, R. (2013). Mechanisms and models of somatic cell reprogramming. Nat. Rev. Genet. 14, 427-439. doi: $10.1038 / \mathrm{nrg} 3473$

Cairo, S., Wang, Y., De Reynies, A., Duroure, K., Dahan, J., Redon, M. J., et al. (2010). Stem cell-like micro-RNA signature driven by Myc in aggressive liver cancer. Proc. Natl. Acad. Sci. U.S.A. 107, 20471-20476. doi: 10.1073/pnas.1009009107

Cao, Y., Guo, W. T., Tian, S., He, X., Wang, X. W., Liu, X., et al. (2015). miR-290/371-Mbd2-Myc circuit regulates glycolytic metabolism to promote pluripotency. EMBO J. 34, 609-623. doi: 10.15252/embj.201490441

Carbognin, E., Betto, R. M., Soriano, M. E., Smith, A. G., and Martello, G. (2016). Stat3 promotes mitochondrial transcription and oxidative respiration during maintenance and induction of naive pluripotency. EMBO J. 35, 618-634. doi: $10.15252 / \mathrm{embj} .201592629$

Card, D. A., Hebbar, P. B., Li, L., Trotter, K. W., Komatsu, Y., Mishina, Y., et al. (2008). Oct4/Sox2-regulated miR-302 targets cyclin D1 in human embryonic stem cells. Mol. Cell. Biol. 28, 6426-6438. doi: 10.1128/MCB.00359-08

Carey, B. W., Finley, L. W., Cross, J. R., Allis, C. D., and Thompson, C. B. (2015). Intracellular alpha-ketoglutarate maintains the pluripotency of embryonic stem cells. Nature 518, 413-416. doi: 10.1038/nature13981

Cartwright, P., Mclean, C., Sheppard, A., Rivett, D., Jones, K., and Dalton, S. (2005). LIF/STAT3 controls ES cell self-renewal and pluripotency by a Myc-dependent mechanism. Development 132, 885-896. doi: 10.1242/dev.01670

Chambers, I., Colby, D., Robertson, M., Nichols, J., Lee, S., Tweedie, S., et al. (2003) Functional expression cloning of Nanog, a pluripotency sustaining factor in embryonic stem cells. Cell 113, 643-655. doi: 10.1016/S0092-8674(03)00392-1 
Chambers, I., Silva, J., Colby, D., Nichols, J., Nijmeijer, B., Robertson, M., et al. (2007). Nanog safeguards pluripotency and mediates germline development. Nature 450, 1230-1234. doi: 10.1038/nature06403

Chang, T. C., Yu, D., Lee, Y. S., Wentzel, E. A., Arking, D. E., West, K. M., et al. (2008). Widespread microRNA repression by Myc contributes to tumorigenesis. Nat. Genet. 40, 43-50. doi: 10.1038/ng.2007.30

Chang, T. C., Zeitels, L. R., Hwang, H. W., Chivukula, R. R., Wentzel, E. A., Dews, M., et al. (2009). Lin-28B transactivation is necessary for Myc-mediated let7 repression and proliferation. Proc. Natl. Acad. Sci. U.S.A. 106, 3384-3389. doi: $10.1073 /$ pnas. 0808300106

Chappell, J., and Dalton, S. (2013). Roles for MYC in the establishment and maintenance of pluripotency. Cold Spring Harb. Perspect. Med. 3:a014381. doi: $10.1101 /$ cshperspect.a014381

Chappell, J., Sun, Y., Singh, A., and Dalton, S. (2013). MYC/MAX control ERK signaling and pluripotency by regulation of dual-specificity phosphatases 2 and 7. Genes Dev. 27, 725-733. doi: 10.1101/gad.211300.112

Charron, J., Malynn, B. A., Fisher, P., Stewart, V., Jeannotte, L., Goff, S. P., et al. (1992). Embryonic lethality in mice homozygous for a targeted disruption of the N-myc gene. Genes Dev. 6, 2248-2257. doi: 10.1101/gad.6.12a.2248

Chen, J., Liu, H., Liu, J., Qi, J., Wei, B., Yang, J., et al. (2013). H3K9 methylation is a barrier during somatic cell reprogramming into iPSCs. Nat. Genet. 45, 34-42. doi: 10.1038/ng.2491

Chen, X., Xu, H., Yuan, P., Fang, F., Huss, M., Vega, V. B., et al. (2008). Integration of external signaling pathways with the core transcriptional network in embryonic stem cells. Cell 133, 1106-1117. doi: 10.1016/j.cell.2008.04.043

Cherry, A. B., and Daley, G. Q. (2012). Reprogramming cellular identity for regenerative medicine. Cell 148, 1110-1122. doi: 10.1016/j.cell.2012.02.031

Choi, Y. J., Lin, C. P., Ho, J. J., He, X., Okada, N., Bu, P., et al. (2011). miR-34 miRNAs provide a barrier for somatic cell reprogramming. Nat. Cell Biol. 13, 1353-1360. doi: 10.1038/ncb2366

Ciriello, G., Miller, M. L., Aksoy, B. A., Senbabaoglu, Y., Schultz, N., and Sander, C. (2013). Emerging landscape of oncogenic signatures across human cancers. Nat. Genet. 45, 1127-1133. doi: 10.1038/ng.2762

Clevers, H., Loh, K. M., and Nusse, R. (2014). Stem cell signaling. An integral program for tissue renewal and regeneration: wht signaling and stem cell control. Science 346:1248012. doi: 10.1126/science. 1248012

Cockburn, K., and Rossant, J. (2010). Making the blastocyst: lessons from the mouse. J. Clin. Invest. 120, 995-1003. doi: 10.1172/JCI41229

Cohen, D. E., and Melton, D. (2011). Turning straw into gold: directing cell fate for regenerative medicine. Nat. Rev. Genet. 12, 243-252. doi: 10.1038/nrg2938

Cole, M. D., and Cowling, V. H. (2008). Transcription-independent functions of MYC: regulation of translation and DNA replication. Nat. Rev. Mol. Cell Biol. 9, 810-815. doi: 10.1038/nrm2467

Cole, M. D., and Nikiforov, M. A. (2006). Transcriptional activation by the Myc oncoprotein. Curr. Top. Microbiol. Immunol. 302, 33-50. doi: 10.1007/3-540-32952-8_2

Cole, M. F., Johnstone, S. E., Newman, J. J., Kagey, M. H., and Young, R. A. (2008). $\mathrm{Tcf} 3$ is an integral component of the core regulatory circuitry of embryonic stem cells. Genes Dev. 22, 746-755. doi: 10.1101/gad.1642408

Cotterman, R., Jin, V. X., Krig, S. R., Lemen, J. M., Wey, A., Farnham, P. J., et al. (2008). N-Myc regulates a widespread euchromatic program in the human genome partially independent of its role as a classical transcription factor. Cancer Res. 68, 9654-9662. doi: 10.1158/0008-5472.CAN-08-1961

Dalton, S. (2015). Linking the cell cycle to cell fate decisions. Trends Cell Biol. 25, 592-600. doi: 10.1016/j.tcb.2015.07.007

Dang, C. V. (2012). MYC on the path to cancer. Cell 149, 22-35. doi: 10.1016/j.cell.2012.03.003

Dang, C. V. (2013). MYC, metabolism, cell growth, and tumorigenesis. Cold Spring Harb. Perspect. Med. 3:a014217. doi: 10.1101/cshperspect.a014217

Das, P. P., Shao, Z., Beyaz, S., Apostolou, E., Pinello, L., De Los Angeles, A., et al. (2014). Distinct and combinatorial functions of Jmjd2b/Kdm $4 \mathrm{~b}$ and $\mathrm{Jmjd} 2 \mathrm{c} / \mathrm{Kdm} 4 \mathrm{c}$ in mouse embryonic stem cell identity. Mol. Cell 53, 32-48. doi: 10.1016/j.molcel.2013.11.011

Davis, A. C., Wims, M., Spotts, G. D., Hann, S. R., and Bradley, A. (1993). A null c-myc mutation causes lethality before 10.5 days of gestation in homozygotes and reduced fertility in heterozygous female mice. Genes Dev. 7, 671-682. doi: 10.1101/gad.7.4.671
Dimos, J. T., Rodolfa, K. T., Niakan, K. K., Weisenthal, L. M., Mitsumoto, H., Chung, W., et al. (2008). Induced pluripotent stem cells generated from patients with ALS can be differentiated into motor neurons. Science 321, 1218-1221. doi: $10.1126 /$ science. 1158799

Dinger, M. E., Amaral, P. P., Mercer, T. R., Pang, K. C., Bruce, S. J., Gardiner, B. B., et al. (2008). Long noncoding RNAs in mouse embryonic stem cell pluripotency and differentiation. Genome Res. 18, 1433-1445. doi: 10.1101/gr.078378.108

Dubois, N. C., Adolphe, C., Ehninger, A., Wang, R. A., Robertson, E. J., and Trumpp, A. (2008). Placental rescue reveals a sole requirement for c-Myc in embryonic erythroblast survival and hematopoietic stem cell function. Development 135, 2455-2465. doi: 10.1242/dev.022707

D'urso, A., and Brickner, J. H. (2014). Mechanisms of epigenetic memory. Trends Genet. 30, 230-236. doi: 10.1016/j.tig.2014.04.004

Efroni, S., Duttagupta, R., Cheng, J., Dehghani, H., Hoeppner, D. J., Dash, C., et al. (2008). Global transcription in pluripotent embryonic stem cells. Cell Stem Cell 2, 437-447. doi: 10.1016/j.stem.2008.03.021

Eilers, M., and Eisenman, R. N. (2008). Myc's broad reach. Genes Dev. 22, 2755-2766. doi: 10.1101/gad.1712408

Evans, M. J., and Kaufman, M. H. (1981). Establishment in culture of pluripotential cells from mouse embryos. Nature 292, 154-156. doi: 10.1038/292154a0

Faast, R., White, J., Cartwright, P., Crocker, L., Sarcevic, B., and Dalton, S. (2004). Cdk6-cyclin D3 activity in murine ES cells is resistant to inhibition by p16(INK4a). Oncogene 23, 491-502. doi: 10.1038/sj.onc.1207133

Fabian, M. R., and Sonenberg, N. (2012). The mechanics of miRNA-mediated gene silencing: a look under the hood of miRISC. Nat. Struct. Mol. Biol. 19, 586-593. doi: $10.1038 / \mathrm{nsmb} .2296$

Fagnocchi, L., Cherubini, A., Hatsuda, H., Fasciani, A., Mazzoleni, S., Poli, V., et al. (2016a). A Myc-driven self-reinforcing regulatory network maintains mouse embryonic stem cell identity. Nat. Commun. 7:11903. doi: 10.1038/ncomms 11903

Fagnocchi, L., Mazzoleni, S., and Zippo, A. (2016b). Integration of signaling pathways with the epigenetic machinery in the maintenance of stem cells. Stem Cells Int. 2016:8652748. doi: 10.1155/2016/8652748

Farrell, A. S., and Sears, R. C. (2014). MYC degradation. Cold Spring Harb. Perspect. Med. 4:a014365. doi: 10.1101/cshperspect.a014365

Fazzio, T. G., Huff, J. T., and Panning, B. (2008). An RNAi screen of chromatin proteins identifies Tip60-p400 as a regulator of embryonic stem cell identity. Cell 134, 162-174. doi: 10.1016/j.cell.2008.05.031

Felsher, D. W., and Bishop, J. M. (1999). Reversible tumorigenesis by MYC in hematopoietic lineages. Mol. Cell 4, 199-207. doi: 10.1016/S1097-2765(00)80367-6

Fernandez, P. C., Frank, S. R., Wang, L., Schroeder, M., Liu, S., Greene, J., et al. (2003). Genomic targets of the human c-Myc protein. Genes Dev. 17, 1115-1129. doi: 10.1101/gad.1067003

Filipczyk, A. A., Laslett, A. L., Mummery, C., and Pera, M. F. (2007). Differentiation is coupled to changes in the cell cycle regulatory apparatus of human embryonic stem cells. Stem Cell Res. 1, 45-60. doi: 10.1016/j.scr.2007.09.002

Fluckiger, A. C., Marcy, G., Marchand, M., Negre, D., Cosset, F. L., Mitalipov, S., et al. (2006). Cell cycle features of primate embryonic stem cells. Stem Cells 24, 547-556. doi: 10.1634/stemcells.2005-0194

Frank, S. R., Parisi, T., Taubert, S., Fernandez, P., Fuchs, M., Chan, H. M., et al. (2003). MYC recruits the TIP60 histone acetyltransferase complex to chromatin. EMBO Rep. 4, 575-580. doi: 10.1038/sj.embor.embor861

Frank, S. R., Schroeder, M., Fernandez, P., Taubert, S., and Amati, B. (2001). Binding of c-Myc to chromatin mediates mitogen-induced acetylation of histone H4 and gene activation. Genes Dev. 15, 2069-2082. doi: 10.1101/gad.906601

Frye, M., Fisher, A. G., and Watt, F. M. (2007). Epidermal stem cells are defined by global histone modifications that are altered by Myc-induced differentiation. PLoS ONE 2:e763. doi: 10.1371/journal.pone.0000763

Fujikura, J., Yamato, E., Yonemura, S., Hosoda, K., Masui, S., Nakao, K., et al. (2002). Differentiation of embryonic stem cells is induced by GATA factors. Genes Dev. 16, 784-789. doi: 10.1101/gad.968802

Gabay, M., Li, Y., and Felsher, D. W. (2014). MYC activation is a hallmark of cancer initiation and maintenance. Cold Spring Harb. Perspect. Med. 4:a014241. doi: $10.1101 /$ cshperspect.a014241 
Gafni, O., Weinberger, L., Mansour, A. A., Manor, Y. S., Chomsky, E., Ben-Yosef, D., et al. (2013). Derivation of novel human ground state naive pluripotent stem cells. Nature 504, 282-286. doi: 10.1038/nature12745

Garcia-Sanz, P., Quintanilla, A., Lafita, M. C., Moreno-Bueno, G., GarciaGutierrez, L., Tabor, V., et al. (2014). Sin3b interacts with Myc and decreases Myc levels. J. Biol. Chem. 289, 22221-22236. doi: 10.1074/jbc.M113.538744

Gaspar-Maia, A., Alajem, A., Meshorer, E., and Ramalho-Santos, M. (2011). Open chromatin in pluripotency and reprogramming. Nat. Rev. Mol. Cell Biol. 12, 36-47. doi: 10.1038/nrm3036

Gaspar-Maia, A., Qadeer, Z. A., Hasson, D., Ratnakumar, K., Leu, N. A., Leroy, G., et al. (2013). MacroH2A histone variants act as a barrier upon reprogramming towards pluripotency. Nat. Commun. 4, 1565. doi: 10.1038/ncomms 2582

Goodrich, D. W., and Lee, W. H. (1992). Abrogation by c-myc of G1 phase arrest induced by RB protein but not by p53. Nature 360, 177-179. doi: $10.1038 / 360177 \mathrm{a} 0$

Greve, T. S., Judson, R. L., and Blelloch, R. (2013). microRNA control of mouse and human pluripotent stem cell behavior. Annu. Rev. Cell Dev. Biol. 29, 213-239. doi: 10.1146/annurev-cellbio-101512-122343

Grskovic, M., Javaherian, A., Strulovici, B., and Daley, G. Q. (2011). Induced pluripotent stem cells-opportunities for disease modelling and drug discovery. Nat. Rev. Drug Discov. 10, 915-929. doi: 10.1038/nrd3577

Gu, W., Gaeta, X., Sahakyan, A., Chan, A. B., Hong, C. S., Kim, R., et al. (2016). Glycolytic metabolism plays a functional role in regulating human pluripotent stem cell state. Cell Stem Cell 19, 476-490. doi: 10.1016/j.stem.2016.08.008

Guccione, E., Martinato, F., Finocchiaro, G., Luzi, L., Tizzoni, L., Dall' Olio, V., et al. (2006). Myc-binding-site recognition in the human genome is determined by chromatin context. Nat. Cell Biol. 8, 764-770. doi: 10.1038/ncb1434

Guttman, M., Amit, I., Garber, M., French, C., Lin, M. F., Feldser, D., et al. (2009). Chromatin signature reveals over a thousand highly conserved large non-coding RNAs in mammals. Nature 458, 223-227. doi: 10.1038/nature07672

Guttman, M., and Rinn, J. L. (2012). Modular regulatory principles of large non-coding RNAs. Nature 482, 339-346. doi: 10.1038/nature10887

Guttman, M., Donaghey, J., Carey, B. W., Garber, M., Grenier, J. K., Munson, G., et al. (2011). lincRNAs act in the circuitry controlling pluripotency and differentiation. Nature 477, 295-300. doi: 10.1038/nature10398

Guttman, M., Garber, M., Levin, J. Z., Donaghey, J., Robinson, J., Adiconis, X., et al. (2010). Ab initio reconstruction of cell type-specific transcriptomes in mouse reveals the conserved multi-exonic structure of lincRNAs. Nat. Biotechnol. 28, 503-510. doi: 10.1038/nbt.1633

Hann, S. R. (2014). MYC cofactors: molecular switches controlling diverse biological outcomes. Cold Spring Harb. Perspect. Med. 4:a014399. doi: 10.1101/cshperspect.a014399

Hatton, K. S., Mahon, K., Chin, L., Chiu, F. C., Lee, H. W., Peng, D., et al. (1996). Expression and activity of L-Myc in normal mouse development. Mol. Cell. Biol. 16, 1794-1804. doi: 10.1128/MCB.16.4.1794

Hayward, W. S., Neel, B. G., and Astrin, S. M. (1981). Activation of a cellular onc gene by promoter insertion in ALV-induced lymphoid leukosis. Nature 290, 475-480. doi: 10.1038/290475a0

Herkert, B., and Eilers, M. (2010). Transcriptional repression: the dark side of myc. Genes Cancer 1, 580-586. doi: 10.1177/1947601910379012

Ho, L., Miller, E. L., Ronan, J. L., Ho, W. Q., Jothi, R., and Crabtree, G. R. (2011). esBAF facilitates pluripotency by conditioning the genome for LIF/STAT3 signalling and by regulating polycomb function. Nat. Cell Biol. 13, 903-913. doi: $10.1038 /$ ncb 2285

Hu, G., and Wade, P. A. (2012). NuRD and pluripotency: a complex balancing act. Cell Stem Cell 10, 497-503. doi: 10.1016/j.stem.2012.04.011

Hu, G., Kim, J., Xu, Q., Leng, Y., Orkin, S. H., and Elledge, S. J. (2009). A genome-wide RNAi screen identifies a new transcriptional module required for self-renewal. Genes Dev. 23, 837-848. doi: 10.1101/gad.1769609

Huangfu, D., Osafune, K., Maehr, R., Guo, W., Eijkelenboom, A., Chen, S., et al. (2008). Induction of pluripotent stem cells from primary human fibroblasts with only Oct4 and Sox2. Nat. Biotechnol. 26, 1269-1275. doi: 10.1038/nbt.1502

Jain, M., Arvanitis, C., Chu, K., Dewey, W., Leonhardt, E., Trinh, M., et al. (2002). Sustained loss of a neoplastic phenotype by brief inactivation of MYC. Science 297, 102-104. doi: 10.1126/science.1071489

Judson, R. L., Babiarz, J. E., Venere, M., and Blelloch, R. (2009). Embryonic stem cell-specific microRNAs promote induced pluripotency. Nat. Biotechnol. 27, 459-461. doi: 10.1038/nbt.1535
Kanellopoulou, C., Muljo, S. A., Kung, A. L., Ganesan, S., Drapkin, R., Jenuwein, T., et al. (2005). Dicer-deficient mouse embryonic stem cells are defective in differentiation and centromeric silencing. Genes Dev. 19, 489-501. doi: 10.1101/gad.1248505

Karwacki-Neisius, V., Goke, J., Osorno, R., Halbritter, F., Ng, J. H., Weisse, A. Y., et al. (2013). Reduced Oct4 expression directs a robust pluripotent state with distinct signaling activity and increased enhancer occupancy by Oct4 and Nanog. Cell Stem Cell 12, 531-545. doi: 10.1016/j.stem.2013.04.023

Keller, G. (2005). Embryonic stem cell differentiation: emergence of a new era in biology and medicine. Genes Dev. 19, 1129-1155. doi: 10.1101/gad.1303605

Kidder, B. L., Yang, J., and Palmer, S. (2008). Stat3 and c-Myc genomewide promoter occupancy in embryonic stem cells. PLoS ONE 3:e3932. doi: 10.1371/journal.pone.0003932

Kim, J., and Zaret, K. S. (2015). Reprogramming of human cancer cells to pluripotency for models of cancer progression. EMBO J. 34, 739-747. doi: $10.15252 / \mathrm{embj} .201490736$

Kim, J., Chu, J., Shen, X., Wang, J., and Orkin, S. H. (2008). An extended transcriptional network for pluripotency of embryonic stem cells. Cell 132, 1049-1061. doi: 10.1016/j.cell.2008.02.039

Kim, J., Woo, A. J., Chu, J., Snow, J. W., Fujiwara, Y., Kim, C. G., et al. (2010). A Myc network accounts for similarities between embryonic stem and cancer cell transcription programs. Cell 143, 313-324. doi: 10.1016/j.cell.2010. 09.010

Knoepfler, P. S., Zhang, X. Y., Cheng, P. F., Gafken, P. R., Mcmahon, S. B., and Eisenman, R. N. (2006). Myc influences global chromatin structure. EMBO J. 25, 2723-2734. doi: 10.1038/sj.emboj.7601152

Krepelova, A., Neri, F., Maldotti, M., Rapelli, S., and Oliviero, S. (2014). Myc and max genome-wide binding sites analysis links the Myc regulatory network with the polycomb and the core pluripotency networks in mouse embryonic stem cells. PLoS ONE 9:e88933. doi: 10.1371/journal.pone.0088933

Kress, T. R., Sabo, A., and Amati, B. (2015). MYC: connecting selective transcriptional control to global RNA production. Nat. Rev. Cancer 15, 593-607. doi: $10.1038 / \mathrm{nrc} 3984$

Land, H., Parada, L. F., and Weinberg, R. A. (1983). Tumorigenic conversion of primary embryo fibroblasts requires at least two cooperating oncogenes. Nature 304, 596-602. doi: 10.1038/304596a0

Laplane, L., Beke, A., Vainchenker, W., and Solary, E. (2015). Concise review: induced pluripotent stem cells as new model systems in oncology. Stem Cells 33, 2887-2892. doi: 10.1002/stem.2099

Laurenti, E., Varnum-Finney, B., Wilson, A., Ferrero, I., Blanco-Bose, W. E., Ehninger, A., et al. (2008). Hematopoietic stem cell function and survival depend on c-Myc and N-Myc activity. Cell Stem Cell 3, 611-624. doi: $10.1016 /$ j.stem.2008.09.005

Lee, S. H., Chen, T. Y., Dhar, S. S., Gu, B., Chen, K., Kim, Y. Z., et al. (2016). A feedback loop comprising PRMT7 and miR-24-2 interplays with Oct4, Nanog, Klf4 and c-Myc to regulate stemness. Nucleic Acids Res. 44, 10603-10618. doi: 10.1093/nar/gkw788

Lee, T. I., Jenner, R. G., Boyer, L. A., Guenther, M. G., Levine, S. S., Kumar, R. M., et al. (2006). Control of developmental regulators by Polycomb in human embryonic stem cells. Cell 125, 301-313. doi: 10.1016/j.cell.2006.02.043

Leese, H. J. (2012). Metabolism of the preimplantation embryo: 40 years on. Reproduction 143, 417-427. doi: 10.1530/REP-11-0484

Levens, D. (2010). You don't muck with MYC. Genes Cancer 1, 547-554. doi: $10.1177 / 1947601910377492$

Liang, J., Wan, M., Zhang, Y., Gu, P., Xin, H., Jung, S. Y., et al. (2008). Nanog and Oct4 associate with unique transcriptional repression complexes in embryonic stem cells. Nat. Cell Biol. 10, 731-739. doi: 10.1038/ncb1736

Lin, C. H., Jackson, A. L., Guo, J., Linsley, P. S., and Eisenman, R. N. (2009a). Mycregulated microRNAs attenuate embryonic stem cell differentiation. EMBO J. 28, 3157-3170. doi: 10.1038/emboj.2009.254

Lin, C. H., Lin, C., Tanaka, H., Fero, M. L., and Eisenman, R. N. (2009b). Gene regulation and epigenetic remodeling in murine embryonic stem cells by c-Myc. PLoS ONE 4:e7839. doi: 10.1371/journal.pone.0007839

Lin, C. Y., Loven, J., Rahl, P. B., Paranal, R. M., Burge, C. B., Bradner, J. E., et al. (2012). Transcriptional amplification in tumor cells with elevated c-Myc. Cell 151, 56-67. doi: 10.1016/j.cell.2012.08.026

Loewer, S., Cabili, M. N., Guttman, M., Loh, Y. H., Thomas, K., Park, I. H., et al. (2010). Large intergenic non-coding RNA-RoR modulates reprogramming 
of human induced pluripotent stem cells. Nat. Genet. 42, 1113-1117. doi: 10.1038/ng.710

Loh, Y. H., Wu, Q., Chew, J. L., Vega, V. B., Zhang, W., Chen, X., et al. (2006). The Oct 4 and Nanog transcription network regulates pluripotency in mouse embryonic stem cells. Nat. Genet. 38, 431-440. doi: 10.1038/ng1760

Lunt, S. Y., and Vander Heiden, M. G. (2011). Aerobic glycolysis: meeting the metabolic requirements of cell proliferation. Annu. Rev. Cell Dev. Biol. 27, 441-464. doi: 10.1146/annurev-cellbio-092910-154237

Mac Auley, A., Werb, Z., and Mirkes, P. E. (1993). Characterization of the unusually rapid cell cycles during rat gastrulation. Development 117, 873-883.

Malynn, B. A., De Alboran, I. M., O'hagan, R. C., Bronson, R., Davidson, L., Depinho, R. A., et al. (2000). N-myc can functionally replace c-myc in murine development, cellular growth, and differentiation. Genes Dev. 14, 1390-1399. doi: $10.1101 / \mathrm{gad} .14 .11 .1390$

Marks, H., Kalkan, T., Menafra, R., Denissov, S., Jones, K., Hofemeister, H., et al. (2012). The transcriptional and epigenomic foundations of ground state pluripotency. Cell 149, 590-604. doi: 10.1016/j.cell.2012.03.026

Marson, A., Levine, S. S., Cole, M. F., Frampton, G. M., Brambrink, T., Johnstone, S., et al. (2008). Connecting microRNA genes to the core transcriptional regulatory circuitry of embryonic stem cells. Cell 134, 521-533. doi: $10.1016 /$ j.cell.2008.07.020

Martin, G. R. (1981). Isolation of a pluripotent cell line from early mouse embryos cultured in medium conditioned by teratocarcinoma stem cells. Proc. Natl. Acad. Sci. U.S.A. 78, 7634-7638. doi: 10.1073/pnas.78.12.7634

Masui, S., Nakatake, Y., Toyooka, Y., Shimosato, D., Yagi, R., Takahashi, K., et al. (2007). Pluripotency governed by Sox 2 via regulation of Oct $3 / 4$ expression in mouse embryonic stem cells. Nat. Cell Biol. 9, 625-635. doi: 10.1038/ncb1589

Mcdonel, P., Demmers, J., Tan, D. W., Watt, F., and Hendrich, B. D. (2012). Sin3a is essential for the genome integrity and viability of pluripotent cells. Dev. Biol. 363, 62-73. doi: 10.1016/j.ydbio.2011.12.019

Mcmahon, S. B., Wood, M. A., and Cole, M. D. (2000). The essential cofactor TRRAP recruits the histone acetyltransferase hGCN5 to c-Myc. Mol. Cell. Biol. 20, 556-562. doi: 10.1128/MCB.20.2.556-562.2000

Melton, C., Judson, R. L., and Blelloch, R. (2010). Opposing microRNA families regulate self-renewal in mouse embryonic stem cells. Nature 463, 621-626. doi: $10.1038 /$ nature 08725

Meshorer, E., and Misteli, T. (2006). Chromatin in pluripotent embryonic stem cells and differentiation. Nat. Rev. Mol. Cell Biol. 7, 540-546. doi: $10.1038 / \mathrm{nrm} 1938$

Mikkelsen, T. S., Hanna, J., Zhang, X., Ku, M., Wernig, M., Schorderet, P., et al. (2008). Dissecting direct reprogramming through integrative genomic analysis. Nature 454, 49-55. doi: 10.1038/nature07056

Mikkelsen, T. S., Ku, M., Jaffe, D. B., Issac, B., Lieberman, E., Giannoukos, G., et al. (2007). Genome-wide maps of chromatin state in pluripotent and lineage-committed cells. Nature 448, 553-560. doi: 10.1038/nature06008

Mitsui, K., Tokuzawa, Y., Itoh, H., Segawa, K., Murakami, M., Takahashi, K., et al. (2003). The homeoprotein Nanog is required for maintenance of pluripotency in mouse epiblast and ES cells. Cell 113, 631-642. doi: $10.1016 /$ S0092-8674(03)00393-3

Moazed, D. (2011). Mechanisms for the inheritance of chromatin states. Cell 146, 510-518. doi: 10.1016/j.cell.2011.07.013

Moussaieff, A., Kogan, N. M., and Aberdam, D. (2015a). Concise review: energy metabolites: key mediators of the epigenetic state of pluripotency. Stem Cells 33, 2374-2380. doi: 10.1002/stem.2041

Moussaieff, A., Rouleau, M., Kitsberg, D., Cohen, M., Levy, G., Barasch, D., et al. (2015b). Glycolysis-mediated changes in acetyl-CoA and histone acetylation control the early differentiation of embryonic stem cells. Cell Metab. 21, 392-402. doi: 10.1016/j.cmet.2015.02.002

Murchison, E. P., Partridge, J. F., Tam, O. H., Cheloufi, S., and Hannon, G. J. (2005). Characterization of Dicer-deficient murine embryonic stem cells. Proc. Natl. Acad. Sci. U.S.A. 102, 12135-12140. doi: 10.1073/pnas.0505479102

Nakagawa, M., Koyanagi, M., Tanabe, K., Takahashi, K., Ichisaka, T., Aoi, T., et al. (2008). Generation of induced pluripotent stem cells without Myc from mouse and human fibroblasts. Nat. Biotechnol. 26, 101-106. doi: 10.1038/nbt1374

Nakagawa, M., Takizawa, N., Narita, M., Ichisaka, T., and Yamanaka, S. (2010). Promotion of direct reprogramming by transformation-deficient Myc. Proc. Natl. Acad. Sci. U.S.A. 107, 14152-14157. doi: 10.1073/pnas.1009374107
Nashun, B., Hill, P. W., and Hajkova, P. (2015). Reprogramming of cell fate: epigenetic memory and the erasure of memories past. EMBO J. 34, 1296-1308. doi: $10.15252 / \mathrm{embj} .201490649$

Neganova, I., Tilgner, K., Buskin, A., Paraskevopoulou, I., Atkinson, S. P., Peberdy, D., et al. (2014). CDK1 plays an important role in the maintenance of pluripotency and genomic stability in human pluripotent stem cells. Cell Death Dis. 5, e1508. doi: 10.1038/cddis.2014.464

Neganova, I., Vilella, F., Atkinson, S. P., Lloret, M., Passos, J. F., Von Zglinicki, T., et al. (2011). An important role for CDK2 in G1 to S checkpoint activation and DNA damage response in human embryonic stem cells. Stem Cells 29, 651-659. doi: $10.1002 /$ stem. 620

Neganova, I., Zhang, X., Atkinson, S., and Lako, M. (2009). Expression and functional analysis of G1 to $\mathrm{S}$ regulatory components reveals an important role for CDK2 in cell cycle regulation in human embryonic stem cells. Oncogene 28, 20-30. doi: 10.1038/onc.2008.358

Neri, F., Zippo, A., Krepelova, A., Cherubini, A., Rocchigiani, M., and Oliviero, S. (2012). Myc regulates the transcription of the PRC2 gene to control the expression of developmental genes in embryonic stem cells. Mol. Cell. Biol. 32, 840-851. doi: 10.1128/MCB.06148-11

Ng, H. H., and Surani, M. A. (2011). The transcriptional and signalling networks of pluripotency. Nat. Cell Biol. 13, 490-496. doi: 10.1038/ncb0511-490

Ng, S. Y., Johnson, R., and Stanton, L. W. (2012). Human long non-coding RNAs promote pluripotency and neuronal differentiation by association with chromatin modifiers and transcription factors. EMBO J. 31, 522-533. doi: 10.1038/emboj.2011.459

Nichols, J., Zevnik, B., Anastassiadis, K., Niwa, H., Klewe-Nebenius, D., Chambers, I., et al. (1998). Formation of pluripotent stem cells in the mammalian embryo depends on the POU transcription factor Oct4. Cell 95, 379-391. doi: 10.1016/S0092-8674(00)81769-9

Nie, Z., Hu, G., Wei, G., Cui, K., Yamane, A., Resch, W., et al. (2012). c-Myc is a universal amplifier of expressed genes in lymphocytes and embryonic stem cells. Cell 151, 68-79. doi: 10.1016/j.cell.2012.08.033

Niwa, H. (2010). Mouse ES cell culture system as a model of development. Dev. Growth Differ. 52, 275-283. doi: 10.1111/j.1440-169X.2009.01166.x

Niwa, H., Burdon, T., Chambers, I., and Smith, A. (1998). Self-renewal of pluripotent embryonic stem cells is mediated via activation of STAT3. Genes Dev. 12, 2048-2060. doi: 10.1101/gad.12.13.2048

Okita, K., Ichisaka, T., and Yamanaka, S. (2007). Generation of germlinecompetent induced pluripotent stem cells. Nature 448, 313-317. doi: 10.1038/nature05934

Pan, G., Tian, S., Nie, J., Yang, C., Ruotti, V., Wei, H., et al. (2007). Whole-genome analysis of histone $\mathrm{H} 3$ lysine 4 and lysine 27 methylation in human embryonic stem cells. Cell Stem Cell 1, 299-312. doi: 10.1016/j.stem.2007.08.003

Park, I. H., Arora, N., Huo, H., Maherali, N., Ahfeldt, T., Shimamura, A., et al. (2008). Disease-specific induced pluripotent stem cells. Cell 134, 877-886. doi: 10.1016/j.cell.2008.07.041

Pasque, V., Radzisheuskaya, A., Gillich, A., Halley-Stott, R. P., Panamarova, M., Zernicka-Goetz, M., et al. (2012). Histone variant macroH2A marks embryonic differentiation in vivo and acts as an epigenetic barrier to induced pluripotency. J. Cell Sci. 125, 6094-6104. doi: 10.1242/jcs.113019

Pauklin, S., and Vallier, L. (2013). The cell-cycle state of stem cells determines cell fate propensity. Cell 155, 135-147. doi: 10.1016/j.cell.2013.08.031

Pelengaris, S., Khan, M., and Evan, G. I. (2002). Suppression of Mycinduced apoptosis in beta cells exposes multiple oncogenic properties of Myc and triggers carcinogenic progression. Cell 109, 321-334. doi: 10.1016/S0092-8674(02)00738-9

Power, M. A., and Tam, P. P. (1993). Onset of gastrulation, morphogenesis and somitogenesis in mouse embryos displaying compensatory growth. Anat. Embryol. 187, 493-504. doi: 10.1007/BF00174425

Psathas, J. N., and Thomas-Tikhonenko, A. (2014). MYC and the art of microRNA maintenance. Cold Spring Harb. Perspect. Med. 4:a014175. doi: 10.1101/cshperspect.a014175

Ringrose, L., and Paro, R. (2004). Epigenetic regulation of cellular memory by the Polycomb and Trithorax group proteins. Annu. Rev. Genet. 38, 413-443. doi: 10.1146/annurev.genet.38.072902.091907

Robinton, D. A., and Daley, G. Q. (2012). The promise of induced pluripotent stem cells in research and therapy. Nature 481, 295-305. doi: 10.1038/nature10761 
Rosa, A., and Ballarino, M. (2016). Long noncoding RNA regulation of pluripotency. Stem Cells Int. 2016:1797692. doi: 10.1155/2016/1797692

Rosa, A., and Brivanlou, A. H. (2013). Regulatory non-coding RNAs in pluripotent stem cells. Int. J. Mol. Sci. 14, 14346-14373. doi: 10.3390/ijms140714346

Rustgi, A. K., Dyson, N., and Bernards, R. (1991). Amino-terminal domains of cmyc and $\mathrm{N}$-myc proteins mediate binding to the retinoblastoma gene product. Nature 352, 541-544. doi: 10.1038/352541a0

Ryall, J. G., Cliff, T., Dalton, S., and Sartorelli, V. (2015). Metabolic reprogramming of stem cell epigenetics. Cell Stem Cell 17, 651-662. doi: 10.1016/j.stem.2015.11.012

Sabo, A., Kress, T. R., Pelizzola, M., De Pretis, S., Gorski, M. M., Tesi, A., et al. (2014). Selective transcriptional regulation by Myc in cellular growth control and lymphomagenesis. Nature 511, 488-492. doi: 10.1038/nature13537

Savatier, P., Huang, S., Szekely, L., Wiman, K. G., and Samarut, J. (1994). Contrasting patterns of retinoblastoma protein expression in mouse embryonic stem cells and embryonic fibroblasts. Oncogene 9, 809-818.

Sawai, S., Shimono, A., Wakamatsu, Y., Palmes, C., Hanaoka, K., and Kondoh, H. (1993). Defects of embryonic organogenesis resulting from targeted disruption of the N-myc gene in the mouse. Development 117, 1445-1455.

Scognamiglio, R., Cabezas-Wallscheid, N., Thier, M. C., Altamura, S., Reyes, A., Prendergast, A. M., et al. (2016). Myc depletion induces a pluripotent dormant state mimicking diapause. Cell 164, 668-680. doi: 10.1016/j.cell.2015.12.033

Sears, R., Nuckolls, F., Haura, E., Taya, Y., Tamai, K., and Nevins, J. R. (2000), Multiple Ras-dependent phosphorylation pathways regulate Myc protein stability. Genes Dev. 14, 2501-2514. doi: 10.1101/gad.836800

Sela, Y., Molotski, N., Golan, S., Itskovitz-Eldor, J., and Soen, Y. (2012). Human embryonic stem cells exhibit increased propensity to differentiate during the G1 phase prior to phosphorylation of retinoblastoma protein. Stem Cells 30, 1097-1108. doi: 10.1002/stem.1078

Seoane, J., Pouponnot, C., Staller, P., Schader, M., Eilers, M., and Massague, J. (2001). TGFbeta influences Myc, Miz-1 and Smad to control the CDK inhibitor p15INK4b. Nat. Cell Biol. 3, 400-408. doi: 10.1038/35070086

Shachaf, C. M., Kopelman, A. M., Arvanitis, C., Karlsson, A., Beer, S., Mandl, S., et al. (2004). MYC inactivation uncovers pluripotent differentiation and tumour dormancy in hepatocellular cancer. Nature 431, 1112-1117. doi: $10.1038 /$ nature 03043

Sheik Mohamed, J., Gaughwin, P. M., Lim, B., Robson, P., and Lipovich, L. (2010). Conserved long noncoding RNAs transcriptionally regulated by Oct4 and Nanog modulate pluripotency in mouse embryonic stem cells. RNA 16, 324-337. doi: 10.1261/rna.1441510

Shipony, Z., Mukamel, Z., Cohen, N. M., Landan, G., Chomsky, E., Zeliger, S. R., et al. (2014). Dynamic and static maintenance of epigenetic memory in pluripotent and somatic cells. Nature 513, 115-119. doi: 10.1038/nature13458

Shiraki, N., Shiraki, Y., Tsuyama, T., Obata, F., Miura, M., Nagae, G., et al. (2014). Methionine metabolism regulates maintenance and differentiation of human pluripotent stem cells. Cell Metab. 19, 780-794. doi: 10.1016/j.cmet.2014.03.017

Shyh-Chang, N., and Daley, G. Q. (2013). Lin28: primal regulator of growth and metabolism in stem cells. Cell Stem Cell 12, 395-406. doi: 10.1016/j.stem.2013.03.005

Shyh-Chang, N., Locasale, J. W., Lyssiotis, C. A., Zheng, Y., Teo, R. Y., Ratanasirintrawoot, S., et al. (2013). Influence of threonine metabolism on S-adenosylmethionine and histone methylation. Science 339, 222-226. doi: $10.1126 /$ science. 1226603

Silva, J., Nichols, J., Theunissen, T. W., Guo, G., Van Oosten, A. L., Barrandon, O., et al. (2009). Nanog is the gateway to the pluripotent ground state. Cell 138, 722-737. doi: 10.1016/j.cell.2009.07.039

Singh, A. M., and Dalton, S. (2009). The cell cycle and Myc intersect with mechanisms that regulate pluripotency and reprogramming. Cell Stem Cell 5, 141-149. doi: 10.1016/j.stem.2009.07.003

Smith, A. G., Heath, J. K., Donaldson, D. D., Wong, G. G., Moreau, J., Stahl, M., et al. (1988). Inhibition of pluripotential embryonic stem cell differentiation by purified polypeptides. Nature 336, 688-690. doi: 10.1038/336688a0

Smith, K. N., Lim, J. M., Wells, L., and Dalton, S. (2011). Myc orchestrates a regulatory network required for the establishment and maintenance of pluripotency. Cell Cycle 10, 592-597. doi: 10.4161/cc.10.4.14792

Smith, K. N., Singh, A. M., and Dalton, S. (2010). Myc represses primitive endoderm differentiation in pluripotent stem cells. Cell Stem Cell 7, 343-354. doi: $10.1016 /$ j.stem.2010.06.023
Smith, K., and Dalton, S. (2010). Myc transcription factors: key regulators behind establishment and maintenance of pluripotency. Regen. Med. 5, 947-959. doi: $10.2217 /$ rme.10.79

Snow, M. H. L. (1977). Gastrulation in the mouse: growth and regionalization of the epiblast. Development 42, 293-303.

Sodir, N. M., Swigart, L. B., Karnezis, A. N., Hanahan, D., Evan, G. I., and Soucek, L. (2011). Endogenous Myc maintains the tumor microenvironment. Genes Dev. 25, 907-916. doi: 10.1101/gad.2038411

Solomon, D. L., Amati, B., and Land, H. (1993). Distinct DNA binding preferences for the c-Myc/Max and Max/Max dimers. Nucleic Acids Res. 21, 5372-5376. doi: $10.1093 /$ nar/21.23.5372

Soucek, L., Whitfield, J., Martins, C. P., Finch, A. J., Murphy, D. J., Sodir, N. M., et al. (2008). Modelling Myc inhibition as a cancer therapy. Nature 455, 679-683. doi: $10.1038 /$ nature 07260

Soufi, A., Donahue, G., and Zaret, K. S. (2012). Facilitators and impediments of the pluripotency reprogramming factors' initial engagement with the genome. Cell 151, 994-1004. doi: 10.1016/j.cell.2012.09.045

Sridharan, R., Gonzales-Cope, M., Chronis, C., Bonora, G., Mckee, R., Huang, C., et al. (2013). Proteomic and genomic approaches reveal critical functions of $\mathrm{H} 3 \mathrm{~K} 9$ methylation and heterochromatin protein-1gamma in reprogramming to pluripotency. Nat. Cell Biol. 15, 872-882. doi: 10.1038/ ncb2768

Sridharan, R., Tchieu, J., Mason, M. J., Yachechko, R., Kuoy, E., Horvath, S., et al. (2009). Role of the murine reprogramming factors in the induction of pluripotency. Cell 136, 364-377. doi: 10.1016/j.cell.2009.01.001

Staller, P., Peukert, K., Kiermaier, A., Seoane, J., Lukas, J., Karsunky, H., et al. (2001). Repression of p15INK4b expression by Myc through association with Miz-1. Nat. Cell Biol. 3, 392-399. doi: 10.1038/35070076

Stanton, B. R., Perkins, A. S., Tessarollo, L., Sassoon, D. A., and Parada, L. F. (1992). Loss of N-myc function results in embryonic lethality and failure of the epithelial component of the embryo to develop. Genes Dev. 6, 2235-2247. doi: 10.1101/gad.6.12a.2235

Stead, E., White, J., Faast, R., Conn, S., Goldstone, S., Rathjen, J., et al. (2002). Pluripotent cell division cycles are driven by ectopic Cdk2, cyclin A/E and E2F activities. Oncogene 21, 8320-8333. doi: 10.1038/sj.onc.1206015

Stine, Z. E., Walton, Z. E., Altman, B. J., Hsieh, A. L., and Dang, C. V. (2015). MYC, metabolism, and cancer. Cancer Discov. 5, 1024-1039. doi: 10.1158/2159-8290.CD-15-0507

Takahashi, K., and Yamanaka, S. (2006). Induction of pluripotent stem cells from mouse embryonic and adult fibroblast cultures by defined factors. Cell 126, 663-676. doi: 10.1016/j.cell.2006.07.024

Takahashi, K., and Yamanaka, S. (2016). A decade of transcription factormediated reprogramming to pluripotency. Nat. Rev. Mol. Cell Biol. 17, 183-193. doi: $10.1038 / \mathrm{nrm} .2016 .8$

Takahashi, K., Tanabe, K., Ohnuki, M., Narita, M., Ichisaka, T., Tomoda, K., et al. (2007). Induction of pluripotent stem cells from adult human fibroblasts by defined factors. Cell 131, 861-872. doi: 10.1016/j.cell.2007.11.019

Tee, W. W., and Reinberg, D. (2014). Chromatin features and the epigenetic regulation of pluripotency states in ESCs. Development 141, 2376-2390. doi: $10.1242 /$ dev.096982

Tesar, P. J., Chenoweth, J. G., Brook, F. A., Davies, T. J., Evans, E. P., Mack, D. L. et al. (2007). New cell lines from mouse epiblast share defining features with human embryonic stem cells. Nature 448, 196-199. doi: 10.1038/nature05972

Theunissen, T. W., and Jaenisch, R. (2014). Molecular control of induced pluripotency. Cell Stem Cell 14, 720-734. doi: 10.1016/j.stem.2014.05.002

Theunissen, T. W., Powell, B. E., Wang, H., Mitalipova, M., Faddah, D. A., Reddy, J., et al. (2014). Systematic identification of culture conditions for induction and maintenance of naive human pluripotency. Cell Stem Cell 15, 471-487. doi: 10.1016/j.stem.2014.07.002

Thomson, J. A., Itskovitz-Eldor, J., Shapiro, S. S., Waknitz, M. A., Swiergiel, J. J., Marshall, V. S., et al. (1998). Embryonic stem cell lines derived from human blastocysts. Science 282, 1145-1147. doi: 10.1126/science.282.5391.1145

Toyooka, Y., Shimosato, D., Murakami, K., Takahashi, K., and Niwa, H. (2008). Identification and characterization of subpopulations in undifferentiated ES cell culture. Development 135, 909-918. doi: 10.1242/dev. 017400

Trounson, A., and Dewitt, N. D. (2016). Pluripotent stem cells progressing to the clinic. Nat. Rev. Mol. Cell Biol. 17, 194-200. doi: 10.1038/nrm.2016.10 
Trumpp, A., Refaeli, Y., Oskarsson, T., Gasser, S., Murphy, M., Martin, G. R., et al. (2001). c-Myc regulates mammalian body size by controlling cell number but not cell size. Nature 414, 768-773. doi: 10.1038/414768a

Tu, W. B., Helander, S., Pilstal, R., Hickman, K. A., Lourenco, C., Jurisica, I., et al. (2015). Myc and its interactors take shape. Biochim. Biophys. Acta 1849, 469-483. doi: 10.1016/j.bbagrm.2014.06.002

Van Blerkom, J. (2009). Mitochondria in early mammalian development. Semin. Cell Dev. Biol. 20, 354-364. doi: 10.1016/j.semcdb.2008.12.005

Van Riggelen, J., Yetil, A., and Felsher, D. W. (2010). MYC as a regulator of ribosome biogenesis and protein synthesis. Nat. Rev. Cancer 10, 301-309. doi: $10.1038 / \mathrm{nrc} 2819$

Vander Heiden, M. G., Cantley, L. C., and Thompson, C. B. (2009). Understanding the Warburg effect: the metabolic requirements of cell proliferation. Science 324, 1029-1033. doi: 10.1126/science. 1160809

Varlakhanova, N. V., Cotterman, R. F., Devries, W. N., Morgan, J., Donahue, L. R., Murray, S., et al. (2010). myc maintains embryonic stem cell pluripotency and self-renewal. Differentiation 80, 9-19. doi: 10.1016/j.diff.2010.05.001

Varlakhanova, N., Cotterman, R., Bradnam, K., Korf, I., and Knoepfler, P. S. (2011). Myc and Miz-1 have coordinate genomic functions including targeting Hox genes in human embryonic stem cells. Epigenetics Chromatin 4:20. doi: 10.1186/1756-8935-4-20

Vennstrom, B., Sheiness, D., Zabielski, J., and Bishop, J. M. (1982). Isolation and characterization of c-myc, a cellular homolog of the oncogene ( $\mathrm{v}-\mathrm{myc}$ ) of avian myelocytomatosis virus strain 29. J. Virol. 42, 773-779.

Walz, S., Lorenzin, F., Morton, J., Wiese, K. E., Von Eyss, B., Herold, S., et al. (2014). Activation and repression by oncogenic MYC shape tumour-specific gene expression profiles. Nature 511, 483-487. doi: 10.1038/nature13473

Wang, F., and Higgins, J. M. (2013). Histone modifications and mitosis: countermarks, landmarks, and bookmarks. Trends Cell Biol. 23, 175-184. doi: 10.1016/j.tcb.2012.11.005

Wang, J., Alexander, P., Wu, L., Hammer, R., Cleaver, O., and Mcknight, S. L. (2009a). Dependence of mouse embryonic stem cells on threonine catabolism. Science 325, 435-439. doi: 10.1126/science. 1173288

Wang, J., Hevi, S., Kurash, J. K., Lei, H., Gay, F., Bajko, J., et al. (2009b). The lysine demethylase LSD1 (KDM1) is required for maintenance of global DNA methylation. Nat. Genet. 41, 125-129. doi: 10.1038/ng.268

Wang, Y., Baskerville, S., Shenoy, A., Babiarz, J. E., Baehner, L., and Blelloch, R. (2008). Embryonic stem cell-specific microRNAs regulate the G1-S transition and promote rapid proliferation. Nat. Genet. 40, 1478-1483. doi: $10.1038 /$ ng. 250

Wang, Y., Medvid, R., Melton, C., Jaenisch, R., and Blelloch, R. (2007). DGCR8 is essential for microRNA biogenesis and silencing of embryonic stem cell self-renewal. Nat. Genet. 39, 380-385. doi: 10.1038/ng1969

Warburg, O. (1956). On the origin of cancer cells. Science 123, 309-314. doi: $10.1126 /$ science. 123.3191 .309

Ware, C. B., Nelson, A. M., Mecham, B., Hesson, J., Zhou, W., Jonlin, E. C., et al. (2014). Derivation of naive human embryonic stem cells. Proc. Natl. Acad. Sci. U.S.A. 111, 4484-4489. doi: 10.1073/pnas.1319738111

Weinberger, L., Ayyash, M., Novershtern, N., and Hanna, J. H. (2016). Dynamic stem cell states: naive to primed pluripotency in rodents and humans. Nat. Rev. Mol. Cell Biol. 17, 155-169. doi: 10.1038/nrm.2015.28

Wernig, M., Meissner, A., Cassady, J. P., and Jaenisch, R. (2008). c-Myc is dispensable for direct reprogramming of mouse fibroblasts. Cell Stem Cell 2, 10-12. doi: 10.1016/j.stem.2007.12.001

White, J., Stead, E., Faast, R., Conn, S., Cartwright, P., and Dalton, S. (2005). Developmental activation of the Rb-E2F pathway and establishment of cell cycle-regulated cyclin-dependent kinase activity during embryonic stem cell differentiation. Mol. Biol. Cell 16, 2018-2027. doi: 10.1091/mbc.E04-12-1056

Williams, R. L., Hilton, D. J., Pease, S., Willson, T. A., Stewart, C. L., Gearing, D. P., et al. (1988). Myeloid leukaemia inhibitory factor maintains the developmental potential of embryonic stem cells. Nature 336, 684-687. doi: 10.1038/336684a0

Wu, S. M., and Hochedlinger, K. (2011). Harnessing the potential of induced pluripotent stem cells for regenerative medicine. Nat. Cell Biol. 13, 497-505. doi: 10.1038/ncb0511-497
Ying, Q. L., Nichols, J., Chambers, I., and Smith, A. (2003). BMP induction of Id proteins suppresses differentiation and sustains embryonic stem cell self-renewal in collaboration with STAT3. Cell 115, 281-292. doi: 10.1016/S0092-8674(03)00847-X

Ying, Q. L., Wray, J., Nichols, J., Batlle-Morera, L., Doble, B., Woodgett, J., et al. (2008). The ground state of embryonic stem cell self-renewal. Nature 453, 519-523. doi: 10.1038/nature06968

Young, R. A. (2011). Control of the embryonic stem cell state. Cell 144, 940-954. doi: 10.1016/j.cell.2011.01.032

Yu, J., Vodyanik, M. A., Smuga-Otto, K., Antosiewicz-Bourget, J., Frane, J. L., Tian, S., et al. (2007). Induced pluripotent stem cell lines derived from human somatic cells. Science 318, 1917-1920. doi: 10.1126/science.1151526

Zeller, K. I., Zhao, X., Lee, C. W., Chiu, K. P., Yao, F., Yustein, J. T., et al. (2006). Global mapping of c-Myc binding sites and target gene networks in human B cells. Proc. Natl. Acad. Sci. U.S.A. 103, 17834-17839. doi: $10.1073 /$ pnas. 0604129103

Zeltner, N., and Studer, L. (2015). Pluripotent stem cell-based disease modeling: current hurdles and future promise. Curr. Opin. Cell Biol. 37, 102-110. doi: $10.1016 /$ j.ceb.2015.10.008

Zhang, J., Khvorostov, I., Hong, J. S., Oktay, Y., Vergnes, L., Nuebel, E., et al. (2011). UCP2 regulates energy metabolism and differentiation potential of human pluripotent stem cells. EMBO J. 30, 4860-4873. doi: 10.1038/emboj.2011.401

Zhang, J., Nuebel, E., Daley, G. Q., Koehler, C. M., and Teitell, M. A. (2012). Metabolic regulation in pluripotent stem cells during reprogramming and self-renewal. Cell Stem Cell 11, 589-595. doi: 10.1016/j.stem.2012.10.005

Zhao, X. D., Han, X., Chew, J. L., Liu, J., Chiu, K. P., Choo, A., et al. (2007). Whole-genome mapping of histone $\mathrm{H} 3$ Lys4 and 27 trimethylations reveals distinct genomic compartments in human embryonic stem cells. Cell Stem Cell 1, 286-298. doi: 10.1016/j.stem.2007.08.004

Zheng, G. X., Do, B. T., Webster, D. E., Khavari, P. A., and Chang, H. Y. (2014). Dicer-microRNA-Myc circuit promotes transcription of hundreds of long noncoding RNAs. Nat. Struct. Mol. Biol. 21, 585-590. doi: 10.1038/nsmb.2842

Zhong, X., Li, N., Liang, S., Huang, Q., Coukos, G., and Zhang, L. (2010). Identification of microRNAs regulating reprogramming factor LIN28 in embryonic stem cells and cancer cells. J. Biol. Chem. 285, 41961-41971. doi: 10.1074/jbc.M110.169607

Zhu, H., Lensch, M. W., Cahan, P., and Daley, G. Q. (2011). Investigating monogenic and complex diseases with pluripotent stem cells. Nat. Rev. Genet. 12, 266-275. doi: 10.1038/nrg2951

Zhu, J., Adli, M., Zou, J. Y., Verstappen, G., Coyne, M., Zhang, X., et al. (2013). Genome-wide chromatin state transitions associated with developmental and environmental cues. Cell 152, 642-654. doi: 10.1016/j.cell.2012.12.033

Zimmerman, K. A., Yancopoulos, G. D., Collum, R. G., Smith, R. K., Kohl, N. E., Denis, K. A., et al. (1986). Differential expression of myc family genes during murine development. Nature 319, 780-783. doi: 10.1038/319780a0

Zippo, A., De Robertis, A., Serafini, R., and Oliviero, S. (2007). PIM1-dependent phosphorylation of histone $\mathrm{H} 3$ at serine 10 is required for MYC-dependent transcriptional activation and oncogenic transformation. Nat. Cell Biol. 9, 932-944. doi: 10.1038/ncb1618

Zippo, A., Serafini, R., Rocchigiani, M., Pennacchini, S., Krepelova, A., and Oliviero, S. (2009). Histone crosstalk between H3S10ph and H4K16ac generates a histone code that mediates transcription elongation. Cell 138, 1122-1136. doi: 10.1016/j.cell.2009.07.031

Conflict of Interest Statement: The authors declare that the research was conducted in the absence of any commercial or financial relationships that could be construed as a potential conflict of interest.

Copyright (c) 2017 Fagnocchi and Zippo. This is an open-access article distributed under the terms of the Creative Commons Attribution License (CC BY). The use, distribution or reproduction in other forums is permitted, provided the original author(s) or licensor are credited and that the original publication in this journal is cited, in accordance with accepted academic practice. No use, distribution or reproduction is permitted which does not comply with these terms. 